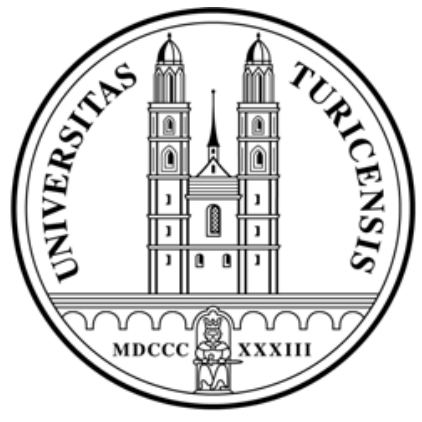

Institute for Empirical Research in Economics

University of Zurich

Working Paper Series

ISSN 1424-0459

Working Paper No. 492

Female Market Work, Tax Regimes, and the Rise of the Service Sector

Michelle Petersen Rendall

Revised version, July 2017 


\title{
Female Market Work, Tax Regimes, and the Rise of the Service Sector*
}

\author{
Michelle Petersen Rendall ${ }^{\dagger}$ \\ The University of Zurich
}

July 9,2017

\begin{abstract}
US regional variation shows a positive correlation between the size of the service economy and female market hours, which is partially driven by different tax regimes. Based on this fact, this paper develops a multi-sector model to: (1) quantify the effect of different tax regimes in incentivizing woman to enter the labor force, and (2) estimate the feedback effect from women entering the labor force on the service sector size. Counterfactual results suggest that tax progressivity has a stronger effect than tax levels on married female market hours and the speed of structural transformation. In addition, married households react more to progressivity increases and single households are more sensitive to level changes. These results highlight that models ignoring tax structures (levels and progressivity) and household heterogeneity (dual versus single earning households) could lead to erroneous policy conclusions.
\end{abstract}

JEL classification: E21, E24, J20, O14.

Keywords: technological progress; sectoral labor allocation; female labor supply; labor demand; taxation.

*I would like to thank Richard Rogerson, Michele Tertilt, two anonymous referees, and seminar and conference participants at the Minneapolis Federal Reserve, New York University, SED Conference in Ghent, University of Arizona, University of Zurich, Virginia Tech, and World Bank for valuable comments. Financial support from the European Research Council (ERC Advanced Grant IPCDP-229883) and the ZUNIV FAN Research Talent Development Fund is gratefully acknowledged. This paper was previously circulated under the title "The Service Sector and Female Market Work."

†University of Zurich, Department of Economics, Schönberggasse $1 \mathrm{CH}-8001$ Zurich.

Email: michelle.rendall@econ.uzh.ch. All errors are mine. 


\section{Introduction}

A growing service sector provides women with better employment opportunities, both in terms of wages and job openings, while a larger female labor force demands more market produced services (e.g., childcare, elderly care, prepared meals) resulting in a larger service sector. However, the extent to which the growth of the service sector and female employment are related crucially depends on the tax regime, as households can allocate time between taxed market work and untaxed home production. Given the policy debate concerning women's employment rates (OECD, 2015a), this paper estimates the effects of tax structures (levels, progressivity, and dual earning households) on female market hours and, consequently, on the rising service sector in the US.

Using US regional data, I document three facts concerning the service sector, female market hours and taxes: (1) metropolitan statistical areas (MSAs) with larger service sectors have higher female market hours; (2) the rise in service hours and female market hours is positively correlated; however, (3) increases in average income tax rates dampen female market hours. Based on these facts, I build a multi-sector model with taxes and structural change to address two questions: (1) how large are the hypothetical costs of introducing high taxes in the US economy, and (2) how important is the feedback effect from (married) women entering the labor market on the service sector size?

The model is based on a standard general equilibrium multi-sector model augmented with an island structure. Islands are useful in modeling (married) women's access to service- versus industry-employment opportunities. Households live on one of two islands, where islands only differ in a female-specific utility cost of finding a service sector job. Households are heterogeneous in family size (married or single, with none or two children) and educational attainment (high school, some college, college, and post-graduate). Households allocate time between the home (production and leisure) and labor market, and choose consumption over three types of goods: market produced services, market produced goods and home-produced services. The model has three key 
assumptions: (1) men are assumed to have equal productivity across sectors, while women have higher productivity in services; (2) women draw sector-specific utility costs of working, and on average prefer service- over industry-jobs; and (3) households can produce a substitute for market produced services (e.g., childcare, elderly care, meals) using goods and time. Standard structural transformation, in combination with the above three assumptions, incentivize women to enter the labor market and substitute home hours with market-purchased services.

The model is calibrated to the 1977 US labor market. I simulate the calibrated model with exogenous changes in tax schedules, household structures (marital status, children, educational attainment) and relative wages from the late 1970s and 2000s. The baseline model can account for the entire rise in both female hours and service-to-industry hours. A decomposition of the female hours trend shows that the model generates the rise in hours through the typical channels, i.e., a closing gender wage gap, increasing educational attainment coupled with higher returns to education, and structural transformation. The decomposition of the sectoral hour trend shows that a fall in industry-to-service hours is partially driven by women's improved labor market opportunities.

To quantitatively address the two proposed research questions, I simulate counterfactual experiments with three different tax regimes: (1) a high tax regime (HTR), higher both in levels and progressivity; (2) a tax regime with the same higher average tax burden, but with a flat tax (no progressivity); and (3) a flat tax with the same average tax burden as the benchmark economy. I focus on two outcomes for each of the three hypothetical tax regimes: (1) changes in male- and female-hours compared to the benchmark, and (2) changes in the size of the service sector due to changing household time allocations and consumption patterns.

Compared against the benchmark, high taxes with progressivity lead to lower hours worked in the market and an increase in home- and leisure-hours. In contrast, a regime with the same tax burden, but a flat tax structure, leads to a much smaller fall in market hours, a fall in leisure hours and an increase in home hours. These opposing results in the allocation of hours between market/home and leisure across the two tax structures is driven by the different reaction of married- 
and single-households. Married households decrease hours when progressivity increases, shifting to both home production and leisure by taking advantage of specialization across spouses. With a flat tax structure, married households do not face the additional marginal tax effect from higher progressivity and react less. In contrast, (poorer) single women (and mothers) shift hours to marketand home-production to compensate for any loss in consumption of goods and services due to a higher average taxes burden.

In the second part of the counterfactual exercise, I decompose the fall in industry-to-service hours into multiple components. The sectoral hours ratio in the model is driven by firms demanding machines for production, and consumers demanding goods and services. In turn, these two demand components are also affected by exogenous technological change. Thus, in the spirit of an OaxacaBlinder decomposition, I decompose the fall in industry-to-service hours into four components, changes in firm/household demand given average technology, and changes in technology given average firm/household demand. In the benchmark, over one-third of the fall in the sectoral hours ratio is explained by changes in consumer demand for market services. The explanatory power of changing consumer demand falls by 17 percentage points for the high-progressive tax regime, but falls by only 7 percentage points for the high-flat tax regime. In contrast, it increases by 4 percentage points for the flat US tax regime. In addition, to determine the feedback of women on the size of the service sector, I further decompose changing household demand by household type (married, single females and males). This decomposition shows that married households can account for a much larger share of the change compared to single households. This is again due to the greater specialization potential of married households. These results highlight that models ignoring tax structures (levels and progressivity) and household heterogeneity (dual versus single earning households) could lead to erroneous policy conclusions. 


\section{Literature Review}

The importance of taxes and structural transformation has been highlighted in multiple crosscountry studies of aggregate hours worked (Prescott, 2004; Rogerson, 2008). Subsequent research points to a lack of the marketization of services, a term coined by Freeman and Schettkat (2005), as a cause for low aggregate hours worked. For example, Ragan (2013) and Olovsson (2009) show that higher European tax rates (compared to the US) motivate individuals to shift hours from the market to the home (or leisure). Duernecker and Herrendorf (2015) show that differences between the US and France stem from a rise in leisure time. This literature models the household as a single representative agent facing different tax levels, while Fang and McDaniel (2017) find that market work and home production vary, to a large extent, when disaggregated by sex. Olivetti and Petrongolo (2014) further show that countries with smaller service sectors have less female employment. These latter results suggest a need to explicitly model both female and male agents to assess the impact of women on economic activity.

By adding a two-person household, the model here features labor force participation both at the intensive- and extensive-margins, similar to Guner, Kaygusuz and Ventura (2013). The authors study the possible aggregate effect of adopting a European-style childcare subsidy scheme in the US. I add multiple sectors to incorporate the effects of structural transformation and leisure to their base model. This is essential, as the counterfactual exercises show different household types react to tax changes in very different ways when allowing for a choice between home and leisure hours. The resulting differing time allocations then change consumption and the size of the service sector. My modeling of tax schedules is based on Holter, Krueger and Stepanchuk (2014) who use a similar joint-decision problem to study the effect of taxes on government revenue.

While this is the first paper to combine taxes, female employment and structural transformation in a single model, there are a number of studies that have analyzed a subset of these three topics. Buera, Kaboski and Zhao (2013) is most similar in spirit to this paper. Omitting taxes and women's 
higher productivity in services, the authors build on the framework of Buera and Kaboski (2012) to study the role of skill, scale and women in the rise of services. The authors find only a very small feedback effect from female employment on services. However, they suggest that the model's inability to match the rise in married women's hours may be the driving force. This missing link, in turn, is likely due to omitting women's sectoral productivity differences and preferences. Ngai and Petrongolo (2017) focus on how much of the closing gender wage- and employmentgaps can be explained by structural change. The authors find that structural change can account for 20 percent of the closing gender wage gap and half of the rise in hours worked. The results are driven by the interaction of women's comparative advantage in services and home production with the process of structural transformation. Also omitting taxes, Akbulut (2011) focuses on explaining the rise in female employment through structural change, assuming women can only work at home or in the service sector. Given the aim of this paper, in addition to the comparative advantage of women in services, I use an exogenously closing wage gap and a preference for service employment (modeled through employment search costs) to generate a rise in female hours as observed in the US. Matching the entire rise in female hours allows the model to quantify the entire feedback effect of women entering the labor market on the service sector size.

Lastly, omitting the structural transformation aspect, Bick and Fuchs-Schuendeln (2012) and Chakraborty, Holter and Stepanchuk (2015) find taxes play a substantial role in explaining differences in hours worked by gender over a large cross-section of countries. Based on this prior research, there is substantial value, especially for policy applications, to analyzing the effects of combining female labor market choices and structural transformation with taxes.

\section{Empirical Trends}

I exploit variation across MSAs, combined with NBER tax data (Feenberg and Coutts, 1993), to show how taxes, the service sector and households' employment decisions are interrelated. By 


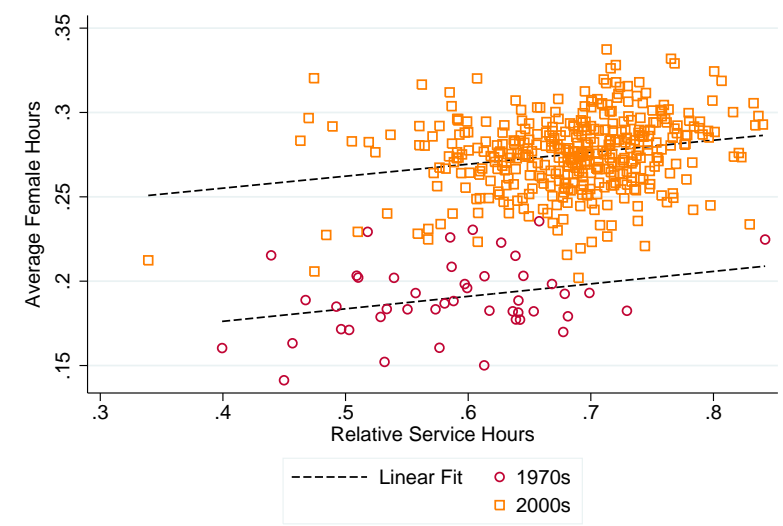

Population Weighted Correlation $=0.36$ and 0.16

(a) Women-to-Services

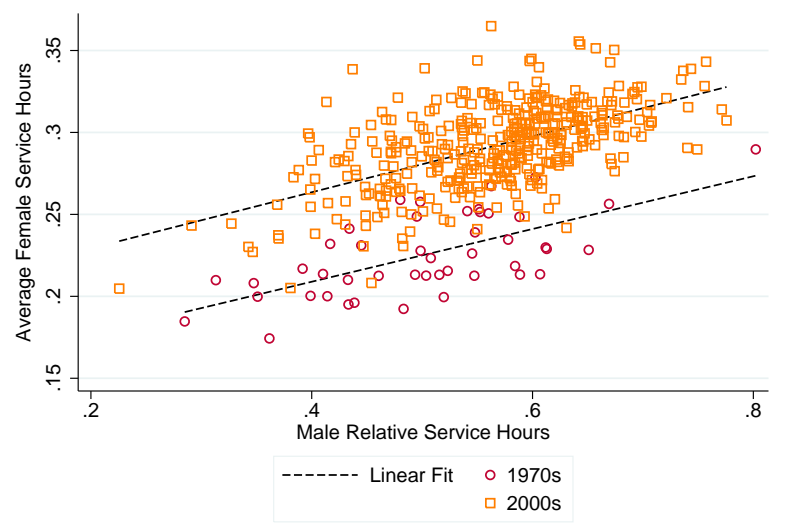

(b) Women-to-Men

Note: Annual hours averaged across households within MSA and decades using population weights. Relative hours refer to service-to-total hours worked within MSA and decade. Correlations are weighted by population size. Source: CPS.

Figure 1: Female Hours-to-Service Correlation across US Metropolitan Statistical Areas

definition, an MSA combines urban agglomerations linked by employment (or other commerce) making it a good approximation for local labor markets. Given the availability of NBER state-level tax data starting in the late-1970s, the analysis focuses on the late-1970s (1977 onward) until 2010.

Figure 1 shows the population-weighted correlation between the share of MSA-wide service hours and average female market hours (left panel) and the correlation between the share of male service hours and average female service market hours (right panel). The correlation is positive between women and the service sector size, but it decreases from 0.36 in the 1970 s to 0.16 by 2010 . The correlation of relative male service hours and women's average hours worked in services is also positive ( 0.74 in the 1970 s and 0.68 in the 2000 s). That is, women tend to work more hours in the service sector in MSAs with larger service sectors, as measured by men's relative hours. In contrast, there is no equivalent positive correlation in hours with the size of the service sector for men in either decade (figure omitted).

Figure 2 graphs changes in average hours worked across the 1970s and 2000s for women/men 


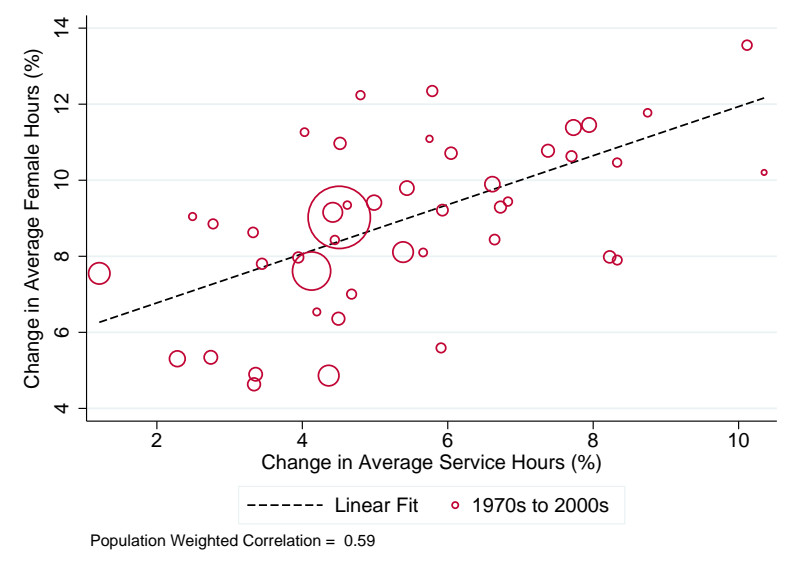

(a) Women

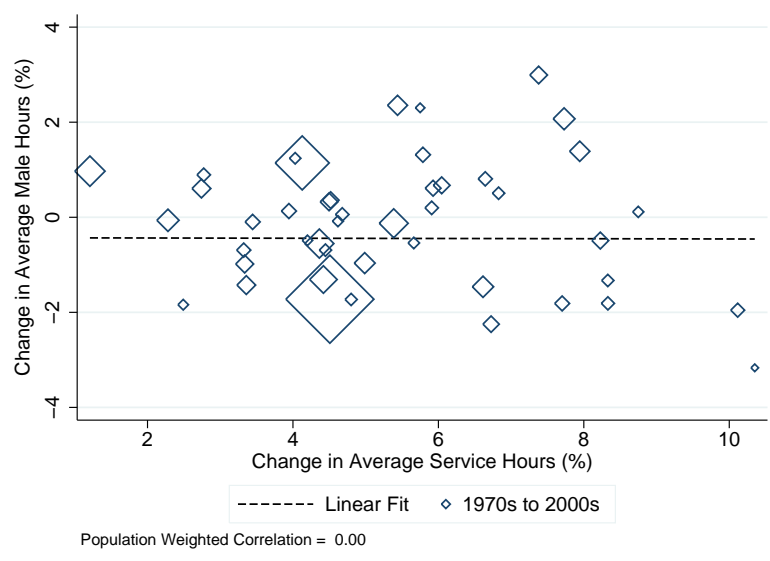

(b) Men

Note: Level changes from the 1970 to 2000 decade in annual hours averaged across households within MSA. Hours correlations are weighted by population size. Source: CPS.

Figure 2: Correlation of 1970-2000 Change in Gender Market Hours and Service Sector Hours

and average service sector hours. The population-weighted correlation between the change of average service hours and female market hours is 0.59 compared to zero for men (the R-squared values are 0.35 and zero, respectively). Areas with the largest increase in female hours also saw the largest increase in average service hours. ${ }^{1}$

Given variation in state income tax laws over time, it is possible to control for changes in average tax rates. I use average tax rates from the US Taxsim Calculator from 1979 to 2010 for a fixed sample of taxpayers in 1984 across all states to only capture changes in tax laws. ${ }^{2}$ Since individuals are taxed in their state of residence and MSAs can span various states, changes in tax rates are averaged by population-weights from each state. Table 1 shows that accounting for tax changes and a number of other cross-MSA differences (e.g., changes in family size, family composition etc.) maintains the correlation between female hours and service hours, but also suggests a negative correlation between the average tax burden that households face and female

\footnotetext{
${ }^{1}$ There are considerably fewer MSAs in the 1970 s CPS survey then in the 2000s. However, when aggregating the results on the state-level instead, the correlation for women is comparable at 0.55 with an R-squared of 0.31 .

${ }^{2}$ For further details on the tax data used in this section, see: www. nber.org/taxs im.
} 
(and male) hours worked. ${ }^{3}$

Table 1: Changes in Labor Market Hours by Gender

\begin{tabular}{|c|c|c|}
\hline & $\begin{array}{c}\Delta H_{f} \\
\text { (1) }\end{array}$ & $\begin{array}{c}\Delta H_{m} \\
(\mathbf{2})\end{array}$ \\
\hline \multirow{2}{*}{$\Delta H_{S}$} & $0.514 * * *$ & -0.104 \\
\hline & $(0.108)$ & $(0.088)$ \\
\hline \multirow[t]{2}{*}{$\Delta$ Avg. Tax Burden } & $-0.540 *$ & -0.104 \\
\hline & $(0.285)$ & $(0.334)$ \\
\hline \multirow[t]{2}{*}{$\Delta$ Spouse's Hours } & $0.423 * *$ & $0.401 * * *$ \\
\hline & $(0.175)$ & $(0.142)$ \\
\hline \multirow[t]{2}{*}{$\Delta$ Married } & -0.125 & $0.173^{*}$ \\
\hline & $(0.082)$ & $(0.099)$ \\
\hline \multirow[t]{2}{*}{$\Delta \#$ Children } & $-0.086^{* * *}$ & 0.034 \\
\hline & $(0.022)$ & $(0.025)$ \\
\hline \multirow[t]{2}{*}{$\Delta$ Fraction Child under 5} & $-0.202 * *$ & $0.358 * * *$ \\
\hline & $(0.085)$ & $(0.082)$ \\
\hline Observations & 45 & 45 \\
\hline R-squared & 0.712 & 0.555 \\
\hline \multicolumn{3}{|c|}{$* * * \mathrm{p}<0.01, * * \mathrm{p}<0.05, * \mathrm{p}<0.1$} \\
\hline \multicolumn{3}{|c|}{$\begin{array}{l}\text { Notes: Level changes across household between the } 1970 \text { and } 2000 \text { decades within } \\
\text { MSAs. } H_{f}, H_{m} \text { and } H_{s} \text { refer to average female-, male-, and service-hours. Spouse's } \\
\text { hours refers to male hours in Columns (1) and female hours in Columns (2). Average tax } \\
\text { burden refers to the average tax rate households face. Married refers to the share of mar- } \\
\text { ried households. Number of children refers to average number of children per household. } \\
\text { Fraction child under } 5 \text { indicates the average number of children under age 5. Results are } \\
\text { weighted by population averaged over the two decades. Source: CPS. }\end{array}$} \\
\hline
\end{tabular}

The R-squared from Figure 2 increases from 0.35 to 0.71 (see Column (1)). While every additional one percentage point increase in average service hours increases female hours by half a percentage point $(0.514)$, every additional one percentage point increase in average tax rates decreases female hours by half a percentage point $(-0.540)$. However, in magnitudes, tax increases have been considerably smaller than increases in service employment during this time. For men,

\footnotetext{
${ }^{3}$ The aim here is to establish correlations as motivation for the general equilibrium model/analysis. While establishing causality is not within the scope of this study, I do not rule out that there may be potential endogeneity between hours worked, the size of the tax base and the average tax burden on households.
} 


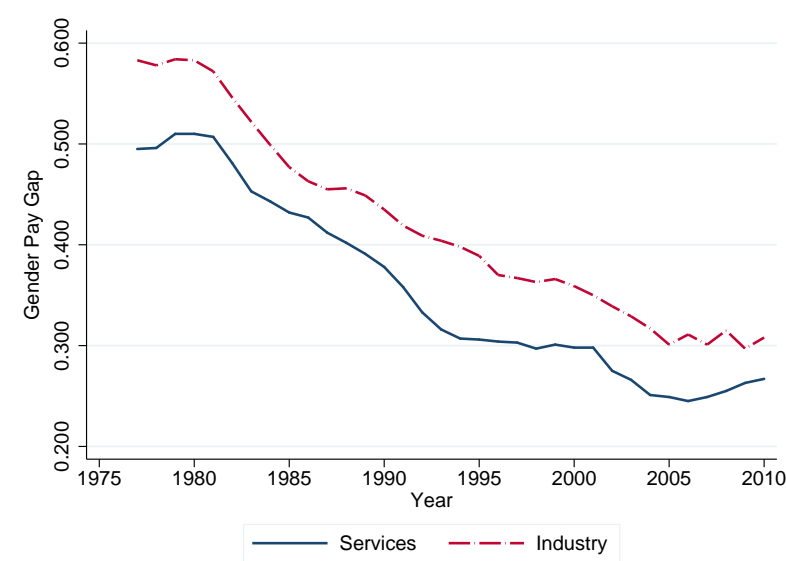

(a) Average

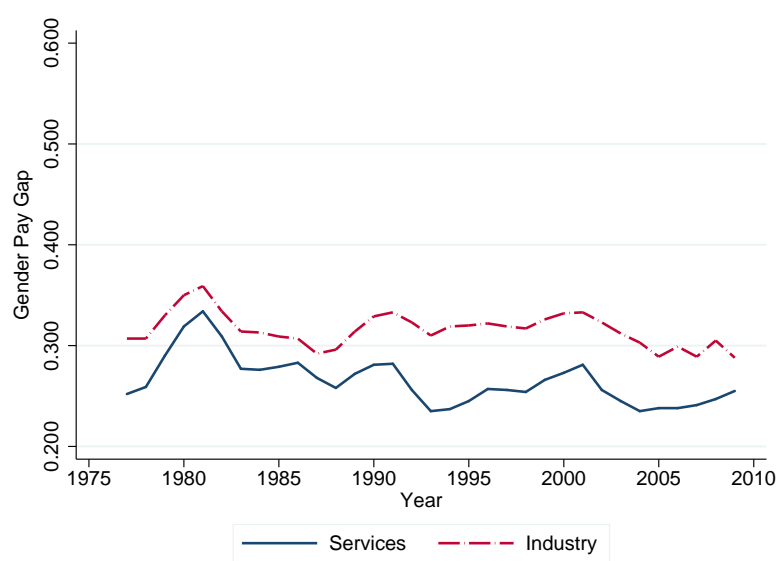

(b) Corrected

Note: The left panel shows the natural logarithm of male-to-female US weekly median wages by sector of individuals working at least 1,400 hours per year. The right panel shows the natural logarithm of male-to-female US weekly median residual wages adjusting for standard selection effects, where the first-stage on female full-time labor market participation controls for education, experience, children under the age of 5, race and the region of work. Source: CPS.

Figure 3: Gender Pay Gap (with and without Self-Selection Correction)

Column (2), the equivalent regression has an R-squared of 0.56. However, the coefficients on service hours and tax rates, while negative, are statistically insignificant. These correlations are robust under a number of specifications including across states and over shorter time intervals. Lastly, demographic controls show the expected signs, i.e., married women are less likely to work, married men are more likely to work, and children decrease female hours, but increase male hours.

There could be many potential reasons why women predominately work in the service sector. I use two mechanisms in the model: (1) women are relatively more productive (earn higher wages) in the service sector; and (2) women have a utility preference for working in office- rather than factory-jobs. These two assumptions are motivated by prior research (Rendall, 2017; Goldin, 1990) and wage gap estimates from the CPS. Figure 3 graphs the natural logarithm of male-to-female US weekly median wages by sector of individuals working at least 1,400 hours per year. The left panel shows the gender pay gap for the industry- and service-sectors, while the right panel shows 
the same gender pay gaps corrected for selection bias using the Heckman correction. The wage gap in services is consistently smaller even when correcting for selection. On average, controlling for selection can account for 20 percent of the difference between the two sectors' gender pay gaps.

Table 2 shows the breakdown of the gender pay gap across decades. In the late-1970s, selection Table 2: Gender Pay Gap by Decade (General and Corrected)

\begin{tabular}{ccccc} 
& \multicolumn{2}{c}{ General } & \multicolumn{2}{c}{ Selection-Corrected } \\
& Services & Industry & Services & Industry \\
\hline $1970 \mathrm{~s}$ & 0.50 & 0.58 & 0.27 & 0.32 \\
$1980 \mathrm{~s}$ & 0.45 & 0.50 & 0.28 & 0.32 \\
$1990 \mathrm{~s}$ & 0.32 & 0.39 & 0.26 & 0.32 \\
$2000 \mathrm{~s}$ & 0.27 & 0.32 & 0.25 & 0.31 \\
\hline
\end{tabular}

Note: Decade averages computed from the estimates in Figure 3. Source: CPS.

can account for over 60 percent $\left(\frac{(0.32-0.27)}{(0.58-0.50)}\right)$ of the pay gap difference between sectors. By the late-2000s, selection accounts for nothing. Rendall (2017) provides one potential explanation for this persistent gap by observing that industry occupations usually require more physical- ("brawn") than intellectual-skills ("brain"), with women having a comparative advantage in brain.

Given the above facts, this study argues that women enter the labor market as the service sector grows, assuming the household tax burden is not high enough to be a disincentive.

\section{General Equilibrium Model}

Given the empirical facts, the economy consists of four islands, two production island $S$ and $G$ and two islands where households live, islands $A$ and $B$. There are two competitive production sectors, goods and services, located on islands $G$ and $S$, respectively. Individuals are "born" on either island $A$ or $B$ and remain there for their lifetime - they live for two periods. The only difference between the islands is the utility cost of finding a service sector job, i.e., it is less costly (easier) to 
find a service-sector job from island $A$. That is, geographically, islands $A$ and $B$ are equidistant to island $G$, but island $A$ is closer to island $S$. A government taxes labor and redistributes revenue as lump-sum payments. Labor reallocation is driven, as in Rogerson (2008), by both non-homothetic preferences and differential sectoral productivity growth.

\subsection{Households}

The structure is a stationary overlapping generations model with a continuum of households. Households consist of either one- or two-adult units. Before entering the productive economy, individuals (1) draw an education level, (2) have their marital status determined, (3) learn the number of children they will have, and (4) learn which island they are living on. There is no bargaining and all households solve a unitary utility function. Each period, households decide on hours in the labor market and home, and consume market goods, home production and leisure time.

Demographics For tractability, household types do not change over time - they are born with a certain marital status, education level and number of children. Women and men, $i \in\{f, m\}$, are

either single or married, $j \in\{s, p\}$. Whether a household has children is determined exogenously at the beginning of period one. Households with children have two, $z \in\{0,2\}$, who live with their parents when young. Individuals are endowed with an exogenous education level (high school, some college, college or post-graduate), $e \in\{1,2,3,4\}$.

Childcare Cost Children come with two types of costs: (1) an economy of scale parameter, $v_{j z}$, reflecting the number of adults and children consuming all goods (purchased and produced at home); and (2) specific childcare costs in terms of service consumption, $\kappa$. This childcare cost can either be purchased on the market or produced at home. In consumption units, childcare at home and in the market carry the same cost. To keep things tractable, women that work in the labor market cannot produce childcare at home. 
Islands and Disutility of Work To account for the variance in women's working behavior, I assume that working women draw a utility cost of working, $\zeta^{x}$, which differs between the service and goods sector, $x \in\{s, g\}$. Women know their realization of these costs, $\zeta^{x} \sim N\left(\mu_{\zeta^{x}}, \sigma_{\zeta^{x}}\right)$, when deciding to enter the labor market. Disutility of work should be thought of not only containing preferences regarding work environment or working colleagues, but also search effort in finding a suitable job and/or commuting time to work. The geographic assumption on islands suggests that it should be easier to find a service job with a pleasant work environment and a potentially shorter commuting time from island $A$ than $B$. Ergo, island $A$ has a smaller mean disutility of work in services, $\mu_{\zeta^{s}}^{A}<\mu_{\zeta^{s}}^{B}$, with the superscript denoting island type. The disutility of work in the goods-producing sector is assumed to be equal across islands. The share of women born on each island is a factor, $\chi$, of the relative hours share of services - based on Figure $1 \mathrm{~b}$ the more people (husbands) work in services, the more women are born on island $A$. Men have no preference over employment by sector.

Productivity Education and experience determine productivity. Efficiency market hours are $\hat{h}_{a}\left(h_{a}, e\right) \equiv \varepsilon_{a} h_{a}$, where $h_{a}$ are actual hours worked and $\varepsilon_{a}$ is productivity at age $a \in\{1,2\}$. Productivity when old depends on working choices when young, $\varepsilon_{2}\left(h_{1}\right)$ - i.e., agents accumulate work experience. If an individual works at least 20 percent of his/her time, market productivity increases by a fixed percentage. ${ }^{4}$ On the flip side, individuals that do not work will experience skill depreciation (decreasing productivity). Hourly wages, when young, are a function of an individual's education level, $e$, and (potentially) the sector of work, $x$, differentiated by gender, $i$, to allow for discrimination or productivity differences, $\omega_{1 i, t}=w_{t} \varepsilon_{1 i}(e, x)$. In the second period, when old, hourly wages are a function of past work experience, initial education level and the sector of employment, $\omega_{2 i, t}=w_{t} \varepsilon_{2 i}\left(e, x, h_{1}\right)$. The only measurable differences between the sexes are mar-

\footnotetext{
${ }^{4}$ This equates to 22.4 hours per week, assuming an individual has 16 hours of non-sleeping time per day, 7 days a week. We can think of this threshold as a way of excluding casual/temporary workers with low, often variable, hours and little career development leading to lower welfare compared to regular employees (Esteban-Pretel, Nakajima and Tanaka, 2011). That is, this cut-off can be termed "a labor force attachment threshold."
} 
ket productivity (by sector) and wage discrimination, i.e., for a given education and hours profile, $\varepsilon_{a f} \leq \varepsilon_{a m}$

Preferences Each period, households, married or single, allocate time to: (1) the market $\left(h_{f}, h_{m}\right)$; (2) home production $\left(n_{f}, n_{m}\right)$; and (3) leisure $\left(\ell_{f}, \ell_{m}\right)$. Household income is used to purchase: (1) goods for consumption $\left(c_{g}\right)$, (2) goods for input into home production $(d)$, (3) services in the market $\left(c_{S}\right)$, and (4) childcare $(\kappa)$, if necessary. The household also consumes a home-produced service-substitute. Home-services $\left(c_{n}\right)$ are produced with time and goods as inputs.

The household's utility function with marital status $j$ (dropping time/age subscripts) is,

$$
u(C, L)=\frac{\left(C / v_{j z}\right)^{1-\phi}}{1-\phi}+\psi_{j} \frac{\ell^{1-\sigma}}{1-\sigma}
$$

Households' face a standard budget constraint,

$$
p_{g}\left(c_{g}+d\right)+p_{s}\left(c_{s}+\mathbb{1}_{\left(h_{f}>0, z>0\right)} \kappa\right)=\theta_{0, j z} y^{1-\theta_{1, j z}}+T
$$

and a time allocation constraint,

$$
1=h_{i}+n_{i}+\ell_{i}
$$

Gross income is $y=\omega_{m} h_{m}+\omega_{f} h_{f}$ if married and $y=\omega_{i} h_{i}$ otherwise. The tax structure $\left(\theta_{0} y^{\left(1-\theta_{1}\right)}\right)$ is a standard method of modeling tax levels $\left(\theta_{0}\right)$ and progressivity $\left(\theta_{1}\right)$. The particular advantage of this formulation is that levels and progressivity are independent (Holter, Krueger and Stepanchuk, 2014). Taxes are allowed to vary both in levels and progressivity by household type (marital status and children). Consumption $(C)$ is the composite consumption of services and goods,

$$
C=\left(a_{g} c_{g}^{\varepsilon}+\left(1-a_{g}\right) F\left(\hat{c}_{s}, \hat{c}_{n}\right)^{\varepsilon}\right)^{\frac{1}{\varepsilon}}
$$


where $F\left(\hat{c}_{s}, \hat{c}_{n}\right)$ is a composite service consumption,

$$
F\left(\hat{c}_{s}, \hat{c}_{n}\right)=\left(a_{s}\left(c_{s}-\mathbb{1}_{\left(h_{f}>0, z>0\right)} \kappa\right)^{\rho}+\left(1-a_{s}\right)\left(c_{n}-\mathbb{1}_{\left(h_{f}=0, z>0\right)} \kappa\right)^{\rho}\right)^{\frac{1}{\rho}}
$$

Market-services are composed of two parts, $\hat{c}_{s}=c_{s}-\mathbb{1}_{\left(h_{f}>0, z>0\right)} \kappa$, privately purchased services and childcare. If the woman does not work, childcare is provided at home $\left(\mathbb{1}_{\left(h_{f}=0, z>0\right)} \kappa\right)$. Home production is, as in Greenwood and Guner (2009), a CES function of goods and time, with total factor productivity $A_{n}$,

$$
c_{n}=A_{n}\left(a_{n} d^{\alpha_{d}}+\left(1-a_{n}\right) n^{\alpha_{d}}\right)^{\frac{1}{\alpha_{d}}}
$$

where total hours are a CES of spouses' hours for a married couple,

$$
n=\left(\left(n_{m}\right)^{\alpha_{n}}+\left(n_{f}\right)^{\alpha_{n}}\right)^{\frac{1}{\alpha_{n}}}
$$

with $1>\alpha_{n}>0$ and $n=n_{i}$ for singles. Lastly, the leisure of spouses are assumed to be complements; husbands and wives prefer spending some time together in leisure,

$$
\ell=\left(\left(\ell_{m}\right)^{\alpha_{\ell}}+\left(\ell_{f}\right)^{\alpha_{\ell}}\right)^{\frac{1}{\alpha_{\ell}}}
$$

with $\alpha_{\ell}<0$ and $\ell=\ell_{i}$ for singles.

Decision Problem Given preferences and choices, only work experience when young affects the recursive decision problem. Old households solve the one period problem above, taking into account past work experience through current efficiency units of labor. First, all young households choose work on the intensive margin while taking into account the experience accumulation threshold $\left(h_{1} \geq 0.2\right){ }^{5}$ Second, the problem for young households with children is also characterized by

\footnotetext{
${ }^{5}$ If individuals work fewer hours than 20 percent of their time, i.e., are not attached to the labor market, they lose human capital. If they work above this threshold they gain an experience premium (see paragraph on "Productivity" above).
} 
working on the extensive margin and purchasing childcare services.

For young single men, the state is determined by the education (productivity) level only. ${ }^{6}$ Given the value function $V_{m}(\varepsilon)$, men choose their consumption and time allocation by maximizing,

$$
V_{m}(\varepsilon)=\max _{\left\{c_{g}, d, c_{s}, h, n\right\}} u(C, L)+\beta V_{m}\left(\varepsilon^{\prime}\right)
$$

subject to the Equation (2) and (3) constraints, where $\varepsilon^{\prime}$ denotes the evolution of productivity conditional on hours worked when young.

Single women must additionally decide whether to search for a service sector job or not. The state is determined by home-island location, $I$, the number of children, $z$, and productivity level, $\varepsilon$. Denote the job-specific value functions by $V_{f}^{x}(I, z, \varepsilon)$, where the superscript $(x \in\{s, g\})$ denotes the sector. Alternatively, women can choose not to work in the labor market $\left(h_{f}=0\right.$ and $\left.V_{f}^{0}(I, z, \varepsilon)\right)$. The value function of a single woman in island $I$ is,

$$
V_{f}(I, z, \varepsilon)=\max \left\{V_{f}^{0}(I, z, \varepsilon), V_{f}^{s}(I, z, \varepsilon)-\zeta^{s}, V_{f}^{g}(I, z, \varepsilon)-\zeta^{g}\right\}
$$

For each distinct option the value function follows from the maximization problem conditional on sector choice $\mathrm{x}$,

$$
V_{f}^{x}(I, z, \varepsilon)=\max _{\left\{c_{g}, d, c_{s}, h, n\right\}} u(C, L)+\beta V_{f}\left(I, 0, \varepsilon^{\prime}\right),
$$

subject to the Equation (2) and (3) constraints. The state variables update according to the hours worked when young $\left(\varepsilon^{\prime}\right)$, the fact that children leave the household in period two $(z=0)$ and that agents do not move across islands $\left(I^{\prime}=I\right)$.

The problem of a young married household is almost identical to a single female household with the same state variables. Given the value function $V_{p}\left(I, z, \varepsilon_{m}, \varepsilon_{f}\right)$ for young married house-

\footnotetext{
${ }^{6}$ Productivity and education are identical when young, $e=\varepsilon=e_{1}$.
} 
holds, the household decides whether the wife should work and in which sector,

$$
V_{p}\left(I, z, \varepsilon_{m}, \varepsilon_{f}\right)=\max \left\{V_{p}^{0}\left(I, z, \varepsilon_{m}, \varepsilon_{f}\right), V_{p}^{s}\left(I, z, \varepsilon_{m}, \varepsilon_{f}\right)-\zeta^{s}, V_{p}^{g}\left(I, z, \varepsilon_{m}, \varepsilon_{f}\right)-\zeta^{g}\right\}
$$

The households' consumption and time allocations follow from maximizing,

$$
V_{p}^{x}\left(I, z, \varepsilon_{m}, \varepsilon_{f}\right)=\max _{\left\{c_{g}, d, c_{s}, h_{m}, h_{f}, n_{m}, n_{f}\right\}} u(C, L)+\beta V_{p}\left(I, 0, \varepsilon_{m}^{\prime}, \varepsilon_{f}^{\prime}\right)
$$

subject to the Equation (2) and (3) constraints. State variables update as in the single household problems.

\subsection{Production}

The competitive sectors use labor and machines to produce final goods and services $\left\{Y_{g}, Y_{s}\right\}$. The final sectoral output is Cobb-Douglas in machines, $k_{x}$, and aggregate labor, $L_{x}$,

$$
Y_{x, t}=A_{x, t}^{1-\alpha} k_{x, t}^{\alpha} L_{x, t}^{1-\alpha} \text { for } x=g, s .
$$

Total factor productivity for each sector $x$ is given by $A_{x, t}$, and grows at rate $\gamma_{x}\left(A_{x, t+1}=(1+\right.$ $\left.\left.\gamma_{x}\right) A_{x, t}\right)$. Dropping time subscripts, final goods producers make the static choice of hiring efficiency units of labor, $L_{x}$, at wage rate $w_{x}$ and purchase machines, $k_{x}$, at prices $p_{x}^{k}$ to maximize profits,

$$
\max _{k_{x}, L_{x}} p_{x} Y_{x}-p_{x}^{k} k_{x}-w_{x} L_{x}
$$

Efficiency units of labor are $L_{x}=\sum_{I} \sum_{i, j, z, e_{a}} \pi_{i j z e_{a}}^{I} \hat{h}_{i j z e_{a}}^{I}$, with $\pi_{i j z e_{a}}^{I}$ denoting the share and $\hat{h}_{i j z e_{a}}$ the efficiency hours of individuals of gender $i$, marital status $j$, children $z$, and productivity level $e_{a}$ on island $I{ }^{7}$ To keep the firm's problem tractable, I follow Acemoglu and Zilibotti (2001) by

\footnotetext{
${ }^{7}$ Since the disutility of work is a fixed cost paid only if working, all agents of a certain type (defined by $i, j, z, e_{a}$ ) work the same hours within sector $x$ conditional on working.
} 
assuming that machines are supplied by monopolists. ${ }^{8}$ Monopolists maximize profits,

$$
\max _{k_{x}} p_{x}^{k} k_{x}-p_{g} k_{x}
$$

where each unit of machine requires one unit of the final goods production, $Y_{g}$. Machines depreciate fully each period. Lastly, given perfect mobility of labor across sectors, wage rates equalize at $w=w_{x}$.

\subsection{Government}

The government, who solves a balanced budget, taxes individuals' labor income with a tax schedule of $\left\{\theta_{0, j z}, \theta_{1, j z}\right\}$ depending on marital status $j$ and number of children $z$, in addition to collecting all monopolists' profits $\Pi_{x, t}$. Tax revenues are rebated to households as a lump-sum transfer, $T$, such that rebates equal transfers, $R_{t}+\Pi_{s, t}+\Pi_{g, t}=T_{t}$. Household tax revenue is,

$$
R_{t}=\sum_{I} \sum_{x} \sum_{i, j, z, e_{a}} \pi_{i j z e_{a}}^{I, x} y_{i j z, e_{a}}^{I, x}\left(1-\theta_{0, j z}\left(y_{i j z, e_{a}}^{I, x}\right)^{-\theta_{1, j z}}\right),
$$

where $y_{i j z e_{a}}^{I, x}$ is the household income, $\pi_{i j z e_{a}}^{I, x}$ is the share of individuals of gender $i$, marital status $j$, children $z$, productivity level $e_{a}$ and superscripts denoting the island $I$, with the working choice $x=\{0, s, g\}$ corresponding to not working, working in services or working in the goods sector.

\subsection{Equilibrium}

Given market prices $\left\{w_{t}, p_{g, t}, p_{s, t}, p_{g, t}^{k}, p_{s, t}^{k}\right\}$ and government prices $\left\{\theta_{0, j z}, \theta_{1, j z}\right\}$, an equilibrium is defined by households' allocation $\left\{c_{g, t}, d_{t}, c_{s, t}, h_{m, t}, h_{f, t}, n_{m, t}, n_{f, t}\right\}$, firms' output $\left\{Y_{g, t}, Y_{s, t}\right\}$, monopolists' output $\left\{k_{g, t}, k_{s, t}\right\}$ and the government's allocation $T_{t}$ such that for all $t$ :

\footnotetext{
${ }^{8}$ Equations (20) and (21) in Section 5 highlight how the firm problem simplifies with monopolists providing machines.
} 
1. $\left\{c_{g, t}, d_{t}, c_{s, t}, h_{m, t}, h_{f, t}, n_{m, t}, n_{f, t}\right\}$ solves each (gender/marital status, children, productivity, island) household problem;

2. $\left\{k_{g, t}, k_{s, t}\right\}$ solves the monopolist problem;

3. $\left\{T_{t}\right\}$ solves the government problem; and

4. All markets clear,

a. The labor market, $L_{x, t}^{s}=L_{x, t}^{d}$ for $x=g, s$;

b. The goods market, $C_{g, t}+D_{t}+k_{g, t}+k_{s, t}=Y_{g, t}$; and

c. The service market, $C_{s, t}+K_{s, t}=Y_{s, t}$,

where $C_{g, t}, D_{t}, C_{s, t}$ and $K_{s, t}$ are aggregates of goods, capital for home production, market services, and market-childcare, e.g., aggregate goods consumption is,

$$
C_{g, t}=\sum_{I} \sum_{x} \sum_{i, j, z, e_{a}} \pi_{i j z e_{a}}^{I, x} c_{g, i j z e_{a}, t}^{I, x}
$$

\section{Analytical Results}

The intertemporal decision only exists because of experience accumulation (or the 20 percent labor market attachment threshold). For exposition it is instructive to study the simpler static maximization problem of the old household. Assuming individuals have market productivity $\varepsilon_{2, t}$ or market income $y_{2, t}=w_{t} \varepsilon_{2, t} h_{2, t}$, a household makes four choices on: (1) home production, (2) service consumption, (3) goods consumption, and (4) leisure. All consumption allocations for any given after-tax income can be solved analytically in terms of time allocated to home production, $n .{ }^{9}$ Time subscripts are omitted for all derivations.

\footnotetext{
${ }^{9}$ First order conditions can be found in the Online Appendix O.1.
} 
Home-Produced Services Spouses allocate time to home production according to relative productivity in the labor market,

$$
\frac{n_{f}}{n_{m}}=\underbrace{\left(\frac{\varepsilon_{m}}{\varepsilon_{f}}\right)^{\frac{1}{1-\alpha_{n}}}}_{\Omega_{n}},
$$

and relative time to leisure by,

$$
\frac{\ell_{f}}{\ell_{m}}=\left(\frac{n_{f}}{n_{m}}\right)^{\frac{1-\alpha_{n}}{1-\alpha_{\ell}}}=\left(\frac{\varepsilon_{m}}{\varepsilon_{f}}\right)^{\frac{1}{1-\alpha_{\ell}}} .
$$

Given imperfect substitutability in home hours $\left(0<\alpha_{n}<1\right)$ and complementarity in leisure $\left(\alpha_{\ell}<\right.$ 0 ), the more productive spouse spends relatively less time in home production and consequently more in market production. ${ }^{10}$

Assuming interior solutions for all market hours $\left(h_{f}, h_{m}>0\right)$ and productivity $\varepsilon_{m}>\varepsilon_{f}$, old-age households produce services at home by allocating goods and time at the ratio,

$$
\frac{d}{n}=\underbrace{\left(\frac{a_{n}}{1-a_{n}} \frac{p_{n}}{p_{g}}\left(\Omega_{n}^{\alpha_{n}}+1\right)^{\frac{\alpha_{n}-1}{\alpha_{n}}}\right)^{\frac{1}{1-\alpha_{d}}}}_{\Omega_{d}} .
$$

Goods in home production are a function of home hours, $d=\Omega_{d} n$, where home production is,

$$
c_{n}=A_{n}\left(a_{n} \Omega_{d}^{\alpha_{d}}+\left(1-a_{n}\right)\right)^{\frac{1}{\alpha_{d}}} n .
$$

The price $p_{n}=\theta_{0, j z}\left(1-\theta_{1, j z}\right) y^{-\theta_{1, j z}} \omega_{m}$ is an implicit home production price for time usage. As this price increases through higher wages or lower taxes, the more costly it becomes to work at home (or the more goods relative to time are used in home production). A drop in tax levels (rising $\theta_{0, j z}$ ) results in a proportional increase of the home price across household types. A drop in progressivity (falling $\theta_{1, j z}$ ) has, in addition, an impact at the margin, which is larger for high

\footnotetext{
${ }^{10}$ Note that this result is equivalent to models without home production, where spouses are assumed to have different disutilities of working (e.g., see Guner, Kaygusuz and Ventura, 2013).
} 
income households. Consequently, with a fall in progressivity, dual-earning households are more willing/able to substitute hours for capital than one-person households. A lower goods price, $p_{g}$, also leads to less hours worked at home. In contrast, low labor market productivity, $\Omega_{n}$, results in relatively high hours at home and lower goods purchases. ${ }^{11}$

In summary, home production hours increase with higher taxes and lower wages/productivity. Since two person households can specialize, they can use relatively more hours in home production. This implies that changes in tax levels versus progressivity have different effects across household types (married versus single).

Composite Service Consumption Using Equation (16), market-service consumption can also be written in terms of home production, $\hat{c}_{s}=\Omega_{s} c_{n}$, where

$$
\frac{c_{s}}{c_{n}}=\underbrace{\left(\frac{a_{s}}{\left(1-a_{s}\right) a_{n} A_{n}} \frac{p_{g}}{p_{s}}\left(a_{n}+\left(1-a_{n}\right) \Omega_{d}^{-\alpha_{d}}\right)^{\frac{\alpha_{d}-1}{\alpha_{d}}}\right)^{\frac{1}{1-\rho}}}_{\Omega_{s}} .
$$

As in Ngai and Pissarides (2008), services are marketized if $\frac{c_{s}}{c_{n}}$ rises. For young households with children, the provision of childcare also matters, replacing $c_{s}$ and $c_{n}$ by $\hat{c}_{s}=c_{s}-\mathbb{1}_{\left(h_{f}>0, z>0\right)} \kappa$ or $\hat{c}_{n}=c_{n}-\mathbb{1}_{\left(h_{f}=0, z>0\right)} \kappa$, respectively. Children provide an additional force in the marketization of services if both parents work. If market- and home-services are gross substitutes $(0<\rho<1)$, more expensive inputs into home production have a direct positive effect on market work, as does a rise in $\Omega_{d}$. The second effect follows from the imperfect substitutability of market-services and home-services.

\footnotetext{
${ }^{11}$ A detailed discussion of the level of leisure is omitted here since the result is standard - higher taxes lead to more leisure. In addition, if the curvature on consumption is smaller than on leisure, $0<\phi<\sigma$, wealthier households allocate more time to leisure.
} 
Goods Consumption Using the market consumption allocation, goods consumption can also be written in terms of home production, $c_{g}=\Omega_{g} c_{s}=\Omega_{g} \Omega_{s} c_{n}$, where

$$
\frac{c_{g}}{c_{s}}=\underbrace{\left(\frac{a_{g}}{\left(1-a_{g}\right) a_{s}} \frac{p_{s}}{p_{g}}\left(\frac{c_{s}}{F\left(c_{s}, c_{n}\right)}\right)^{\varepsilon-\rho}\right)^{\frac{1}{1-\varepsilon}}}_{\Omega_{g}} .
$$

The relative consumption allocation is a function of relative prices, $\left(\frac{p_{s}}{p_{g}}\right)$, and relative marketservices to total service consumption, $\left(\frac{c_{s}}{F\left(c_{s}, c_{n}\right)}\right)$.

Firm Allocation Monopolists' profit maximization results in machine supply being a linear function of labor and TFP in the goods sector,

$$
k_{x}=\alpha^{\frac{2}{1-\alpha}} A_{g} L_{x}
$$

Using Equation (19) simplifies the production of goods and services to,

$$
Y_{g}=\alpha^{\frac{2 \alpha}{1-\alpha}} A_{g} L_{g}
$$

and

$$
Y_{s}=\alpha^{\frac{2 \alpha}{1-\alpha}} A_{g}^{\alpha} A_{s}^{1-\alpha} L_{s}
$$

The final production functions are linear in labor. However, a rise in goods productivity, $A_{g}$, matters for both outputs, but more so for goods production. Normalizing the price of goods to one gives the price of services as a function of productivity, $p_{s}=\left(\frac{A_{g}}{A_{s}}\right)^{1-\alpha}$, and the monopolist prices, $p_{x}^{k}=\frac{1}{\alpha}$. Thus, the wage rate is a function of productivity in the goods sector, $w_{t}=(1-\alpha) \alpha^{\frac{2 \alpha}{1-\alpha}} A_{g}$. Technical progress follows from increases in factor productivity, $A_{x}$. A rise in $\frac{A_{g}}{A_{s}}$ leads to structural change or a fall in relative goods-to-service prices, and a rise in wages. 
Sectoral Labor Since aggregate consumption allocations follow from Equation (12), the model cannot be solved explicitly for sectoral labor. However, studying the different aggregate components is illustrative of the forces shaping a fall in the service-to-goods hours ratio. Using market clearing, $Y_{g}=C_{g}+D+k_{g}+k_{s}$ and $Y_{s}=C_{s}+K_{s}$, the efficiency-unit hours ratio is,

$$
\frac{L_{g}}{L_{S}}=\left(\frac{A_{s}}{A_{g}}\right)^{1-\alpha}\left[\frac{C_{g}+D}{C_{S}+K_{s}}+\frac{\alpha^{\frac{2}{1-\alpha}} A_{g}\left(L_{g}+L_{s}\right)}{C_{S}+K_{s}}\right]
$$

There are three components affecting relative hours in this economy. A direct effect through exogenous technical change and two indirect feedback effects through consumer demand and machine requirements.

Whether relative goods-to-service consumption rises or falls with structural transformation (the first term in brackets) depends on the marketization of services, which in turn depends on tax schedules, relative labor productivities and childcare provisions. From Equations (16) - (18), structural change should lead to a fall in the share of relative goods consumption $\left(\frac{C_{g}+D}{C_{s}+K_{s}}\right)$ and, consequently, to an increase in service-to-industry hours. Pushing mothers into the labor market (e.g., through lower taxes) leads to an increase in service consumption through both an income- and substitutioneffect from home produced childcare (and other home production) to market purchased childcare (and home substitutes). In addition, the multiplicative effect of structural transformation should be larger in an economy where taxes are low and individuals have high labor productivity, since marketization of services should be larger.

The second term in brackets is related to machine demand. Increased machine demand dampens the effect of an increase on the service-to-goods labor ratio, since machines are produced in the goods sector, but required for output in both sectors (although capital requirements in the service sector are smaller).

To summarize, industry-to-service hours change due to: (1) structural change, (2) labor choices, and (3) production requirements. The first effect is straight-forward and present in standard models 
of structural transformation. The second effect is where this paper fills a void in determining if dual households and tax progressivity are important. The third effect, also absent in early models of structural transformation, provides a dampening effect, as capital is required in both goods and service production.

\section{Calibration}

Simulating the general equilibrium model presented in Section 4 requires: (1) approximations of the tax schedule faced by households conditional on marital status and children, (2) productivity levels across men and women, and (3) population shares by household type. I use the OECD Committee on Fiscal Affairs (1978) tax/benefit report to derive the tax parameters $\left(\theta_{0, j z}, \theta_{1, j z}\right)$ for the US in 1977 and the OECD (2015b) tax-benefit model to compute the tax schedule in the 2000s. Productivity levels and population shares are computed using the CPS. The remaining model parameters are calibrated to various 1977 US hour and labor force participation targets. ${ }^{12}$

Tax Schedule The OECD tax database allows for the computation of tax payments by marital status, number of children, and whether both spouses work or not. The OECD Committee on Fiscal Affairs (1978) reports gross income and after-tax income from 1974-1976 for single and married households. Married households' tax payments are reported both for one and two working adults with zero or two children. For singles only, rates without children are reported. Taxes paid as a "percent of average worker wage" are reported in a given year. ${ }^{13}$ The OECD (2015b) tax-benefit

\footnotetext{
${ }^{12}$ Moro, Moslehi and Tanaka (2017) show that the growth rate of the market service share only took-off after 1978, while the share of home production only started falling after 1978, making 1977 an ideal starting point for the empirical exercise.

${ }^{13}$ The tax computations for singles are reported at 50, 100, and 200 percent of average wages. The tax payments for married households are reported at 100, 133, 167, 200, and 400 percent. The 400 percent computations assume each spouse earns a wage twice as high as the average worker in the economy, while the remaining percentages assume the primary worker earns 100 percent and the secondary worker's wage ranges from 0 to 100 percent.
} 
model is used to compute tax schedules for the period 2001-2007. ${ }^{14}$ Tax schedules are computed by pooling years within a decade by marital status and number of children,

$$
\log \left(y_{j z, t}^{a}\right)=\theta_{0, j k, t}+\left(1-\theta_{1, j k, t}\right) \log \left(y_{j z, t}\right)+\varepsilon_{j z, t},
$$

where $y_{j z, t}^{a}$ is after-tax income by marital status, $j \in\left\{s, p^{1}, p^{2}\right\}$, and number of children, $z \in\{0,2\}$. Tax schedules distinguish whether both spouses $\left(p^{2}\right)$ or only one spouse works $\left(p^{1}\right)$, since the US features marriage tax penalties. Table 3 summarizes the US tax parameters used in the simulation. The estimated tax parameters suggest a fall in tax levels, but an increase in progressivity from 1977 Table 3: US Tax Schedule by Decade

\begin{tabular}{lcccc} 
& \multicolumn{2}{c}{ 1970s } & \multicolumn{2}{c}{ 2000s } \\
& $\theta_{0, j z}$ & $\theta_{1, j z}$ & $\theta_{0, j z}$ & $\theta_{1, j z}$ \\
\hline \multirow{2}{*}{ Single } & \multirow{2}{*}{0.757} & 0.100 & 0.749 & 0.111 \\
Single-2 children & 0.804 & 0.114 & 0.931 & 0.249 \\
Married $\left(p^{1}\right)$ & & & 0.818 & 0.124 \\
Married $\left(p^{1}\right)-2$ children & & & 0.984 & 0.257 \\
Married $\left(p^{2}\right)$ & 0.791 & 0.103 & 0.805 & 0.125 \\
Married $\left(p^{2}\right)-2$ children & 0.840 & 0.118 & 0.903 & 0.194 \\
\hline
\end{tabular}

Note: Tax parameter estimates from Equation (23) by decade. Column (1) and (3) are tax level parameters. "Married $\left(p^{1}\right)$ " refers to married households with one earner and "Married $\left(p^{2}\right)$ " refers to dual-earner households. Column (2) and (4) are progressivity tax parameters. There is no data to distinguish between $p^{1}$ and $p^{2}$ in 1977. Given that there is no information for singles with children in the 1970s OECD data, tax parameters of "Single2 children" are computed by assuming that the tax/benefits ratio of a "Single"-to-"Married $\left(p^{2}\right)$ " household equals the ratio of a "Single-2 children"-to-"Married $\left(p^{2}\right)$ - 2 children" household, e.g., $\theta_{0, s 2,1977}=\theta_{0, p 2,1977} / \theta_{0, p 0,1977} \times \theta_{0, s 0,1977}$. Source: OECD.

to 2007. These changes are consistent with Petska, Strudler and Petska (n.d.) and Piketty and Saez (2007) who show an increase in progressivity for the bottom 99 percent of households sorted by

\footnotetext{
${ }^{14}$ To avoid capturing policies related strictly to the financial crisis, all exercises are conducted with data up to 2007. However, the results are not sensitive to using later years.
} 
income.

To also account for consumption taxes, the final after tax income is computed using both income tax schedules and consumption tax rates, i.e.,

$$
y_{t}^{a}=\frac{\theta_{0, t} y_{t}^{\left(1-\theta_{1, t}\right)}}{1+\tau_{c, t}},
$$

where $\tau_{c}$ is the average tax on consumption expenditures. Consumption tax is set to 9.1 percent in 1977 and 7.5 percent in 2007 (McDaniel, 2011).

Productivity I follow Guner, Kaygusuz and Ventura (2013) in computing productivity. When young (individuals aged 25-44), productivity levels are set to average weekly wages of full-time workers (by gender/education) relative to the mean weekly wage for a given year. ${ }^{15}$

Productivity levels are computed in two ways for the old. For workers that did not work above the 20 percent labor force attachment threshold when young, productivity levels decrease by a factor $\delta$. Mincer and Ofek (1982) estimate the loss of non-participation to be 2 percent per annum, the value used here and in Guner, Kaygusuz and Ventura (2013). For individuals that work when young, I compute the growth rate of wages by education level for men using the CPS. The growth rate is computed as the ratio of average weekly wages of individuals aged 25-44 to individuals aged 45-64 within a given year. For women, I use this same wage growth rate. Using the male wage growth rate avoids any issue of selection or weak labor force attachment due to children. The resulting productivity levels are listed in Appendix A.

The simulation also allows for female productivity differences across sectors. Women earn the standard wage rate in services, $w_{t}$, but $\tau_{g} w_{t}$ in goods production. The average difference of the selection corrected sectoral gender pay gaps from 1977 to 2007 suggests $\tau_{g}=0.932$ (see Figure 3).

\footnotetext{
${ }^{15}$ Full-time workers are defined as individuals that work at least 1,750 hours per year.
} 
Marital Status The share of individuals in the four education levels with and without children are used to approximate shares of singles with zero or two children in the model. While there is a small share of single men with children in the data, it is negligible and rounded to zero. Consistent with US data in 1977, there are more women than men in the economy. Only individuals that are currently married in the CPS are classified as such in the model. ${ }^{16}$ Given four education types by gender, there are 16 types of married couples. The degree of assortative matching is directly taken from the data (for shares see Appendix A).

A Priori Parameters A number of parameters are set directly (see Table 4). The capital share is set to one-third in market production $(\alpha=0.33)$. In the model, one can either normalize to 1977 productivity levels, $\left\{A_{g}, A_{s}, A_{n}\right\}$, or consumption share parameters, $\left\{a_{g}, a_{s}, a_{n}\right\}$. I choose a combination given computational time requirements. The consumption share on goods, $a_{g}=0.07$, is taken from Rogerson (2008), and the productivity in the goods sector, $A_{g, 1977}$, is calibrated. ${ }^{17}$ In all other sectors productivity is set to one, $A_{s, 1977}=A_{n, 1977}=1$. Productivity growth rates, $\gamma_{x}$, where the next period's productivity is $A_{x, t+1}=\left(1+\gamma_{x}\right) A_{x, t}$, are computed using value added statistics by sector from the 10 -sector database and are similar to other estimates. For example, goods sector TFP versus service sector TFP growth is, $\gamma_{g}-\gamma_{s}=0.0123$, identical to the estimate by Ngai and Petrongolo (2017). Following estimates by Bridgman (2016) for 1980 onward, I set home productivity growth at $\gamma_{n}=0.002$. I furthermore assume that average wages grow at 1.5 percent per annum.

The parameters governing the elasticity of home- and market-services $\left(\frac{1}{1-\rho}\right)$, the elasticity between goods and services $\left(\frac{1}{1-\varepsilon}\right)$, the elasticity of home hours to capital goods $\left(\frac{1}{1-\alpha_{d}}\right)$, and the elasticity of female- to male-hours $\left(\frac{1}{1-\alpha_{n}}\right)$, are taken from previous studies. Various studies have estimated $\rho$ on microeconomic and macroeconomic data. Aguiar and Hurst (2007) find an elastic-

\footnotetext{
${ }^{16}$ While it is possible to also distinguish cohabitation in later years, there is no such information in the 1970s.

${ }^{17} \mathrm{~A}$ calibration of $a_{g}$, while fixing $A_{g}=1$, does not alter the results of the paper. However, given that $a_{g}$ is close to zero, the natural boundary, the calibration does take longer to converge.
} 
Table 4: A Priori Set Model Parameters

\begin{tabular}{ccl} 
& Value & Source \\
\hline Prior Values & & \\
$A_{s}$ & 1.0 & normalized \\
$A_{n}$ & 1.0 & normalized \\
$a_{g}$ & 0.07 & Rogerson $(2008)$ \\
$\gamma_{n}$ & 0.002 & Bridgman (2016) \\
$\gamma_{w}$ & 0.015 & see text \\
$\alpha$ & 0.33 & Kaldor (1957) \\
$\rho$ & 0.565 & Chang and Schorfheide (2003) \\
$\varepsilon$ & -9.0 & Ngai and Pissarides (2008) \\
$\alpha_{d}$ & 0.189 & Greenwood and Guner (2009) \\
$\alpha_{n}$ & 0.67 & Knowles (2013) \\
$d$ & $0.064 \times \overline{y_{t}}$ & Guner, Kaygusuz and Ventura (2013) \\
$\delta$ & 0.02 & Mincer and Ofek (1982) \\
$\phi$ & 1.5 & see text \\
$\beta$ & $0.98^{20}$ & see text \\
$v_{j z}$ & $\{1.0,1.6,1.5,2.1\}$ & Grabka and Frick (2010) \\
\hline Estimated & & \\
$\gamma_{g}$ & 0.0245 & 10-sector database \\
$\gamma_{s}$ & 0.0121 & 10-sector database \\
$\tau_{g}$ & 0.932 & CPS 1977-2010 \\
\hline
\end{tabular}

ity of 1.8 and Chang and Schorfheide (2003) find a value of 2.3; I use the latter estimate, $\rho=0.565$. Ngai and Pissarides (2008) argue that price elasticities for the entire service sector are between - 0.3 and -0.06 . I set this elasticity to -0.1 , implying an $\varepsilon=-9.0$. The elasticity of substitution between time and home capital is set to $\alpha_{d}=0.189$, the value originally estimated in McGrattan, Rogerson and Wright (1997) and used also in Greenwood and Guner (2009). The elasticity of substitution in home hours is set to $\alpha_{n}=0.67$, which corresponds to the value computed by Knowles (2013) from 1975 to 2003 in matching the change in the home-production time ratio for married couples. The curvature on consumption, $\phi$, is set to a standard value of 1.5 and the annual discount factor is set to 0.98. Economies of scales are taken from Grabka and Frick (2010); these OECD economy of scale calculations assume the second adult to be equivalent to adding another "half-adult" 
to consumption and every additional child adding 0.3 to consumption. Lastly, Guner, Kaygusuz and Ventura (2013) estimate childcare cost at 10 percent of average household income for children under age 5 and 7.7 percent for children between 5 and 14. Thus, given the period length of 20 years, I estimate the prorated equivalent childcare cost to be 6.4 percent of average income.

Calibrated Parameters The remaining parameters, $\left\{A_{g}, \alpha_{\ell}, \psi_{p}, \psi_{s}, a_{s}, a_{n}, \sigma, \mu_{\zeta^{s}}^{A}, \mu_{\zeta^{s}}^{B}, \sigma_{\zeta^{s}}, \mu_{\zeta^{g}}\right.$, $\left.\sigma_{\zeta^{g}}, \chi\right\}$ are calibrated to match 1977 data targets listed in Table 5. Although the estimation is performed jointly, some targets are more informative for certain parameters then others. I outline the general intuition below.

Table 5: Calibrated Model Parameters

\begin{tabular}{lcccl} 
& Value & US Data & Model & Source \\
\hline$A_{g, 1977}$ & 4.32 & 78 & 79 & industry-to-service hours \\
$\alpha_{\ell}$ & -6.05 & 47 & 48 & relative male leisure hours \\
$a_{n}$ & 0.40 & 39 & 44 & housewives' hours \\
$a_{s}$ & 0.62 & 57 & 47 & single women's home/market hours \\
$\psi_{p}$ & 0.47 & 39 & 45 & married men's hours \\
$\psi_{s}$ & 1.18 & 33 & 31 & single men's hours \\
$\sigma$ & 2.65 & 0.5 & 0.5 & male Frisch elasticity \\
$\mu_{\zeta^{s}}^{A}$ & 0.01 & 75 & 74 & women in services \\
$\mu_{\zeta^{s}}^{B}$ & 0.09 & 25 & 22 & married women's hours in services \\
$\sigma_{\zeta^{s}}$ & 0.27 & 52 & 58 & married women not in labor force \\
$\mu_{\zeta^{g}}$ & 0.28 & 87 & 87 & female participation ratio island B/A \\
$\sigma_{\zeta^{g}}$ & 4.43 & 79 & 80 & women in services island B/A \\
$\chi$ & 0.80 & 45 & 46 & men in industry \\
\hline
\end{tabular}

Note: Data targets refer to 5-year moving averages of individuals age 25 to 64 . Leisure and home hours are taken from Aguiar and Hurst (2007) and the male Frisch elasticity is a standard value. Hours are reported in weekly working hours (not efficiency-units). All other statistics are in percentage points. Source: CPS.

Goods sector productivity, $A_{g}$, is set to match the industry-to-services hours ratio, $\left(H_{g} / H_{S}\right)$. The elasticity of substitution in leisure, $\alpha_{\ell}$, is calibrated to match relative leisure hours of men and women (Aguiar and Hurst, 2007). ${ }^{18}$ Having pinned down relative leisure hours through the

\footnotetext{
${ }^{18}$ There are various papers that have pointed out the complementarity of leisure for spouses (e.g., see Fang and
} 
elasticity, the home hours of housewives (with no market hours) and the market hours of married men should determine the weights of home production, $a_{n}$, and leisure, $\psi_{p}$. Similarly, market hours of single men and home-to-market hours of single women should fix the weight of leisure for singles, $\psi_{s}$, and the weight of market- versus home-services, $a_{s}$. The curvature on leisure, $\sigma$, is set by matching the male Frisch elasticity. ${ }^{19}$ The disutility of work parameters, $\left\{\mu_{\zeta^{s}}^{A}, \mu_{\zeta^{s}}^{B}, \mu_{\zeta^{g}}\right\}$, are calibrated to match the non-participation of women, the hours worked in services of married women, and the ratio of female labor force participation on island $A$ to $B$. I use the aggregate relative service share of employed women and the ratio of this labor share across the two islands to fix the dispersion of disutilities, $\left\{\sigma_{\zeta^{s}}, \sigma_{\zeta^{g}}\right\}$. Lastly, the share of women born on island $A$ is set to match the share of women married to men working in the service sector in 1977 given the evidence in Figure 1. The key assumption here is that married women are locationally constraint by their husbands' job location. Therefore, women that are married to men working in services must be in a location with a larger service sector, facing a lower cost of finding service sector work (the only difference between islands $A$ and $B$ ).

The model does well in matching most targets (see Table 5). The biggest discrepancy between the data and model is an underestimation of single women's home-to-market hours. The model also overestimates the home hours of married women, market hours of married men, and the nonparticipation of women. These discrepancies are due to the fixed elasticities of substitution between hours of men and women in the market, home and leisure, along with the fully flexible choice on the intensive margin on market hours.

McDaniel, 2017; Schirle, 2008), however there is no consistent estimate for the elasticity.

${ }^{19}$ The Frisch elasticity is the elasticity of labor supply with respect to wages, keeping the marginal utility of consumption constant, $\frac{\ell_{t}}{h_{t}} \frac{1}{\sigma}$, (Olovsson, 2009). 


\section{Results}

Before studying the two research questions stated in the introduction, it is important to verify that the base model produces time trends that align with US data and to understand how these trends are generated.

Table 6 reports trends for (1) hours in the labor market, (2) sectoral hours, (3) participation rates, (4) leisure hours, and (5) Frisch elasticities. The benchmark model generates sizable changes Table 6: US Time Trends (Data vs. Model)

\begin{tabular}{lcccc} 
& \multicolumn{2}{c}{$\mathbf{1 9 7 7}$} & \multicolumn{2}{c}{$\Delta(\mathbf{2 0 0 7 - 1 9 7 7 )}$} \\
& Data & Model & Data & Model \\
\hline Male Hours & 38 & 42 & -0.3 & -7.3 \\
Female Hours & 16 & 12 & 10.3 & 11.1 \\
Single Male Hours & $33^{\star}$ & 31 & 1.5 & -2.8 \\
Married Male Hours & $39^{\star}$ & 45 & 0.1 & -6.7 \\
Single Female Hours & 26 & 27 & 4.8 & 0.5 \\
Married Female Hours & 14 & 8 & 10.6 & 13.0 \\
NILF Married Women (\%) & 52 & 58 & -22.0 & -27.6 \\
\hline Industry-to-Service Hours & $78^{\star}$ & 79 & -33.8 & -31.1 \\
Women Share in Services $(\%)$ & $75^{\star}$ & 74 & 10.5 & 7.2 \\
\hline Male Leisure Hours & 43 & 52 & 4.4 & 6.9 \\
Female Leisure Hours & 49 & 56 & 3.5 & 4.9 \\
\hline Male Frisch elasticity & $0.5^{\star}$ & 0.5 & & 0.2 \\
Female Frisch elasticity & 2.2 & 2.2 & & -1.2 \\
Married Female Frisch elasticity & & 2.5 & $53 \%$ & $59 \%$ \\
\hline
\end{tabular}

Note: Targets used in the calibration are marked with ${ }^{\star}$. Data targets refer to 5-year moving averages of individuals aged 25 to 64 . Hours are reported in weekly working hours. All other statistics are in percentage points. Source: CPS.

over time that are generally consistent with US magnitudes, even though no statistics beyond 1977 are included as targets. More specifically, all the rise in female hours is replicated with a 10.3 versus 11.1 weekly hour increase in the data versus model. This rise is mostly due to changes in married women's hours (10.6 versus 13.0 weekly hours). The fall in non-participation of married 
women is also matched. By 2007, 22 percent more women worked in the labor market in the US, compared to 27.6 percent in the model. Additionally, the share of women working in services increases in both the model and data, with the model generating over 70 percent $(10.5$ percentage points in the data versus 7.2 in the model). The benchmark also replicates most of the fall in industry-to-service hours (-33.8 versus -31.1 percentage points). The model also generates a similar increase in total leisure hours as observed in the data. That is, Aguiar and Hurst (2007) find an increase of 4.4 hours per week for men and 3.5 hours per week for women. Similarly, the model generates a smaller increase for women than men of 4.9 and 6.9 hours per week, respectively, replicating the "catch-up" of men. Lastly, micro estimates for Frisch elasticities range from 0 to 0.5 for men and 0.5 to 2.2 for women (for a survey on Frisch elasticities see Whalen and Reichling, 2017). Having targeted a male Frisch elasticity of 0.5 in 1977, the model generates an elasticity of 0.7 in 2007, while the Frisch elasticities for women are 2.2 and 1.0 in 1977 and 2007, respectively. For married women, the model generates a decrease in the Frisch elasticity of 59 percent from 1977 to 2007. This fall is in range with estimates found by Blau and Kahn (2007), who report a fall in married women's Frisch elasticity of 50 to 56 percent from 1980 to 2000.

In summary, the model does well in replicating female-, service- and leisure-hour trends in the data. However, the benchmark misses the hours trends for men (-0.3 weekly hours in the data versus -7.3 in the model). While the rise in US female market hours is robust, the rise (or fall) in

US male market hours is highly sensitive to the exact time period selected. For example, Aguiar and Hurst (2007) find that total male market hours decrease by 7.0 hours per week from 1975 to 2003, a magnitude in line with the model estimates.

\subsection{Decomposition of Trends}

What accounts for the time trends in the model? The following analysis decomposes married female hours and relative industry-to-service hours. The fall in male hours is mostly explained by changing family composition - the share of single men increases and these men work substantially 


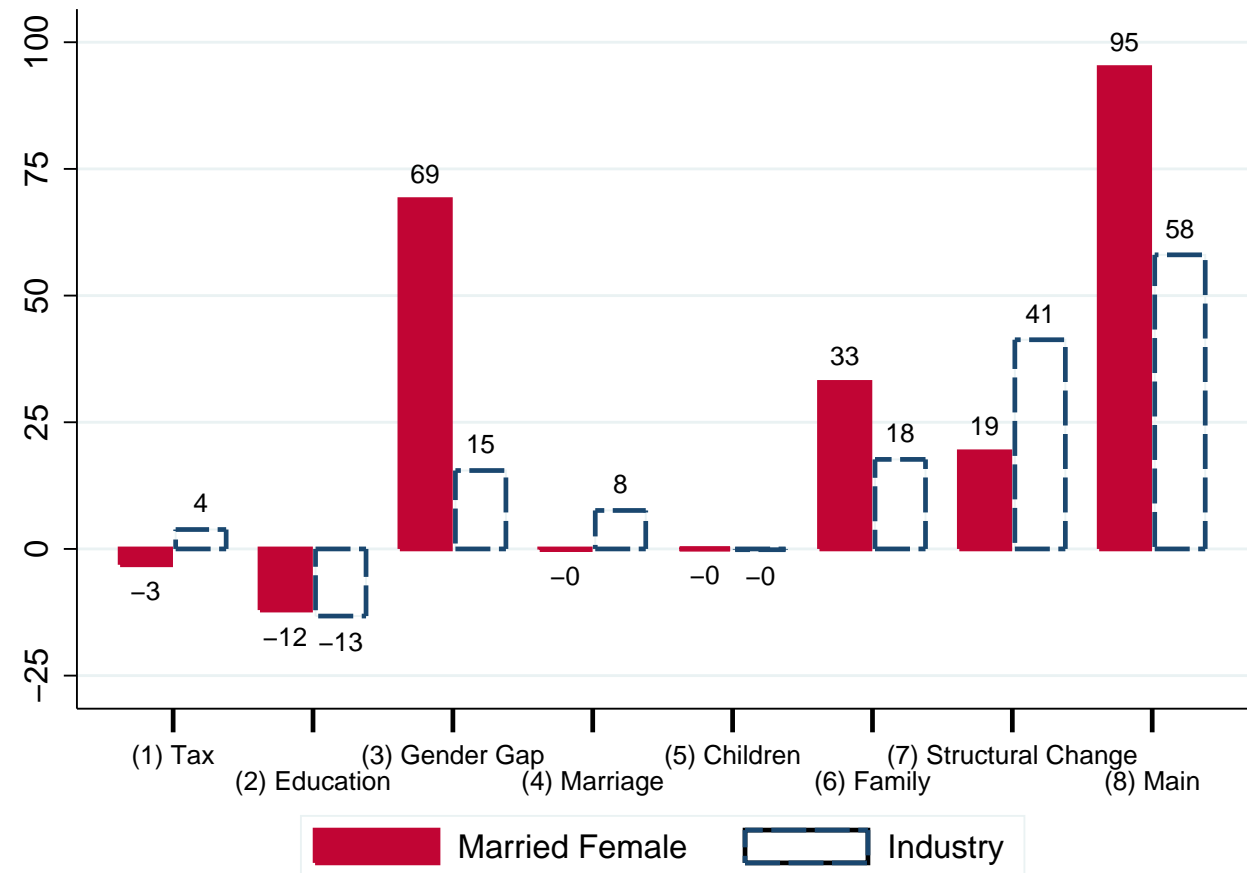

Note: Percent explained of benchmark time trend with each decomposition.

Figure 4: Hours Trend Decomposition

less than married men. Figure 4 shows how hours are affected by different mechanisms in the model. In the figure, all parameters are kept at their 1977 levels and only one set of parameters is allowed to change to their 2007 value. For example, the columns labeled "Tax" only changes the tax schedule $\left(\theta_{0}, \theta_{1}\right)$ to the 2007 values, the remaining parameters (e.g., wage growth, structural transformation) remain fixed at the 1977 level.

Each set of columns (with corresponding labels) graphs the effects for the following experiments,

1. Tax: only tax rates change to the 2007 level

2. Education: returns to education change to the 2007 level

3. Gender: the gender wage gap changes to the 2007 level

4. Marriage: the married share falls to the 2007 values 
5. Children: the share with zero versus two children changes to the 2007 values

6. Family: marriage, parent and education shares are changed

7. Structural Change: only firm market productivities change to the 2007 values

8. Main: combines the Education, Gender, Family and Structural Change experiments

Columns (1) show that changing tax schedules in the US had only a small impact on changing married women's hours and the size of the service sector. This does not mean that tax schedules can be ignored when studying employment trends, but individual small tax changes have a small impact. Experiment (2) shows that a change in education returns without a corresponding supply response has a negative effects on hours worked and the service sector. As the population is assumed to remain at its 1977 distribution, there is group that can take advantage of the rise in the college premium. Columns (3) account for changes in gender discrimination. A general increase in women's productivity has a large impact on married women's hours (similar to Jones, Manuelli and McGrattan, 2015), but a smaller impact on the size of the service sector. The changing gender gap alone can explain 69 percent of the increase in married female hours generated by the base model, but only 15 percent of the fall in the industry-to-service hours ratio. Experiment (4) shows that the fall in marriage rates explains 8 percent of the change in the sectoral hours ratio. This is due to single households producing less at home compared to married households and purchasing more services (including childcare) in the market. Changes in fertility over time have no impact (Columns (5)). However, the population structure undergoes four major changes over time: (1) the marriage rate falls, (2) assortative matching in the marriage market increases, (3) fertility decreases for more educated individuals, and (4) educational attainment increases. All four effects are highly interlinked and, therefore, Experiment (6) combines all these four effects in one counterfactual. Changing family structures can account for one-third of the trend in married female hours and 18 percent of the fall in industry-to-service hours. Columns (7) show that structural changes has a nonnegligible impact on married female hours, accounting for 19 percent of the change, and a larger 
impact on the sectoral hours ratio, accounting for 41 percent of the trend. The result for female hours is similar to Akbulut (2011), who replicates a 25 percent rise in female market hours due to structural change. Lastly, Experiment (8) combines productivity (both individual and sectoral) and family structure to explain most of the rise in married female hours, and over half of the fall in industry-to-service hours. In summary, the effects on married female hours and industry-toservice hours, especially from Experiments (3) - (8), suggest that female work and market services are interlinked.

\subsection{Taxes: Progressivity and Levels}

Prescott (2004) first suggested that higher taxes could explain differences in hours worked between the US and Europe. His original analysis, using a representative single agent model, relied on relatively large Frisch elasticities to explain cross-country differences. Including secondary worker decisions does well in matching trends in hours for the US over time with Frisch elasticities that fall within micro estimates.

Using the benchmark simulation, I conduct three experiments to understand the effect of higher taxes and the differing effects between increasing levels versus progressivity. As a reference point, I compute German taxes from the OECD (2015b) tax-benefit data. Germany is chosen as a representative high tax regime (HTR) in Continental Europe (Holter, Krueger and Stepanchuk, 2014). Table 7 summarizes the tax schedule.

Compared to the US, the HTR taxes both higher in levels and in progressivity. However, there are some differences across marital status and children, with HTR showing relatively more generosity in terms of taxes and benefits towards families - a standard feature of more socially oriented government institutions in Europe (see Figure 5). In a second experiment, in order to disentangle differences between levels and progressivity, I compute a hypothetical tax schedule that produces the same average tax burden as the HTR by only adjusting levels and setting progressivity to zero. As a further comparison I also replicate this same "level" experiment with the US tax 
Table 7: Counterfactual Tax Schedules

\begin{tabular}{lcccccc} 
& \multicolumn{2}{c}{ HTR } & \multicolumn{2}{c}{ Level HTR } & \multicolumn{2}{c}{ Level US } \\
& $\theta_{0, j z}$ & $\theta_{1, j z}$ & $\theta_{0, j z}$ & $\theta_{1, j z}$ & $\theta_{0, j z}$ & $\theta_{1, j z}$ \\
\hline Single & 0.608 & 0.136 & & & & \\
Single-2 children & 0.835 & 0.302 & & & & \\
Married $\left(p^{1}\right)$ & 0.741 & 0.183 & & & & \\
Married $\left(p^{1}\right)-2$ children & 0.890 & 0.284 & 0.755 & 0.000 & 0.817 & 0.000 \\
Married $\left(p^{2}\right)$ & 0.676 & 0.180 & & & & \\
Married $\left(p^{2}\right)-2$ children & 0.774 & 0.232 & & & & \\
\hline
\end{tabular}

Note: See Table 3 for computation of tax level and progressivity in Columns (1) and (2) , respectively. For Columns (3) - (6) all household types face the same tax schedule. These tax parameters are calibrated to match the average tax burden in the HTR or the US benchmark, respectively. Source: OECD.

schedule. These flat tax schedules are summarized in the four rightmost columns of Table 7.

Figure 6 shows how male- and (married) female-hour allocations are affected by higher taxes (and higher levels). Higher taxes distort (decrease) both male and female hours. In the HTR economy, male market hours fall by an additional 3.5 weekly hours compared to the benchmark. These taxes also roughly half the increase in married women's market hours - married women work 7.3 hours less per week than in the 2007 benchmark. Single women's hours are less sensitive to a rise in progressive taxes, as total female market hours fall 0.9 hours per week less. Setting progressivity to zero and only adjusting tax levels has a positive impact on hours for the "Level US" experiment and, consequently, a smaller impact on market hours for both genders in the "Level HTR" experiment (last and second columns, respectively). Focusing on the Level HTR results, while married female market hours contract substantially less $(-0.7$ hours per week compared to the benchmark), total female market hours fall by an additional 0.9 hours per week (a total of 1.6 hours). That is, single women react more to a higher level tax than married women. Equation (15) in Section 5 provides some insight into this result, where a fall in progressivity raises the home price relatively more for high income (dual-earning) households. Ergo, more married women enter 


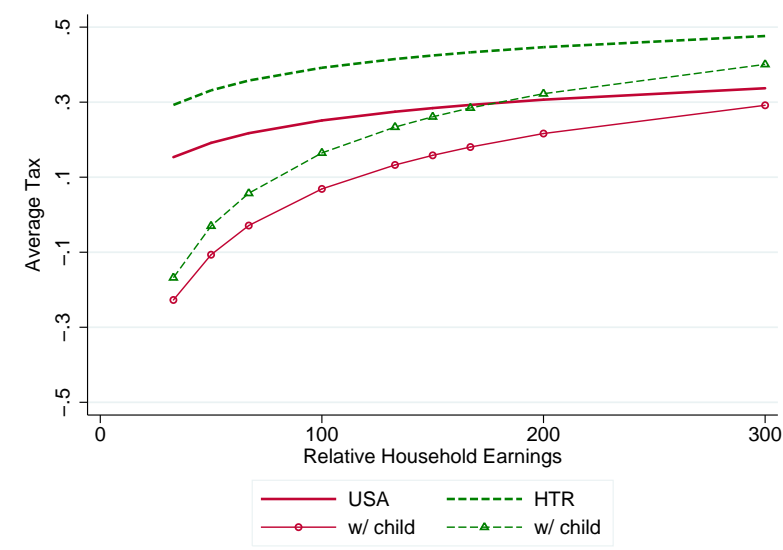

(a) Singles

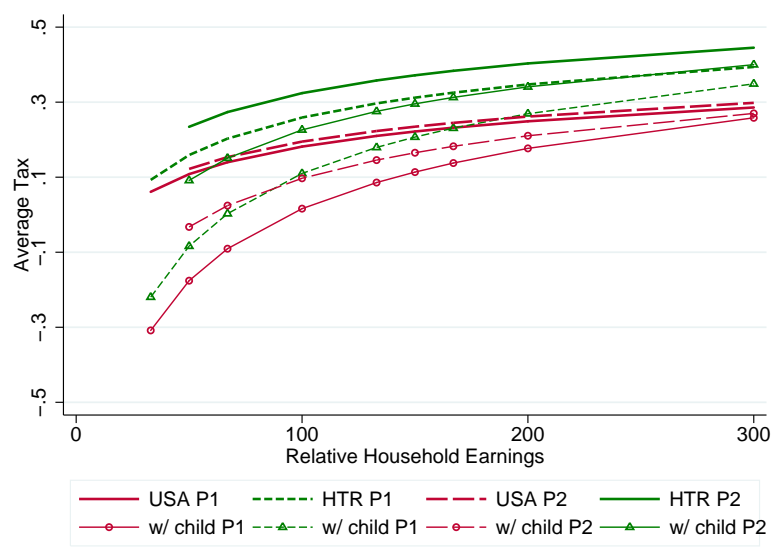

(b) Married

Note: See Tables 3 and 7 for detail of computation. "USA" refers to individuals in the US without children, "USA P1" refers to US married household with one earner no children, and "USA P2" refers to married household with two earning spouses no children. "HTR" refers to the same household types but for the high tax regime. The "w/child" label refers to households by type with two children. Source: OECD.

Figure 5: High Tax Regime (HTR) versus US Tax Functions by Household Composition

the labor market by eliminating progressivity.

Comparing the change in home- versus leisure-hours across the three experiments shows further differences in the underlying mechanism driving low market hours. With zero progressivity, leisure hours fall. In contrast, with high progressivity, individuals shift more hours toward leisure time and, to a lesser degree, home production. This is consistent with Duernecker and Herrendorf (2015) who show that differences between France and the US in hours worked stem from a rise in leisure, not home production. Here, this effect results from different reactions by poor and rich households. In the HTR economy rich households decrease their labor supply and shift hours to leisure time, while poor households shift their hours to home production with flat taxes. Poor households, generally single women, are the "losers" and rich households, generally educated married couples, are the "winners" of a move to flat taxes. ${ }^{20}$ In terms of hours, single females increase their home work by an additional 1.0 hour per week when moving from the HTR schedule to a flat

\footnotetext{
${ }^{20}$ Welfare computations are available upon request.
} 


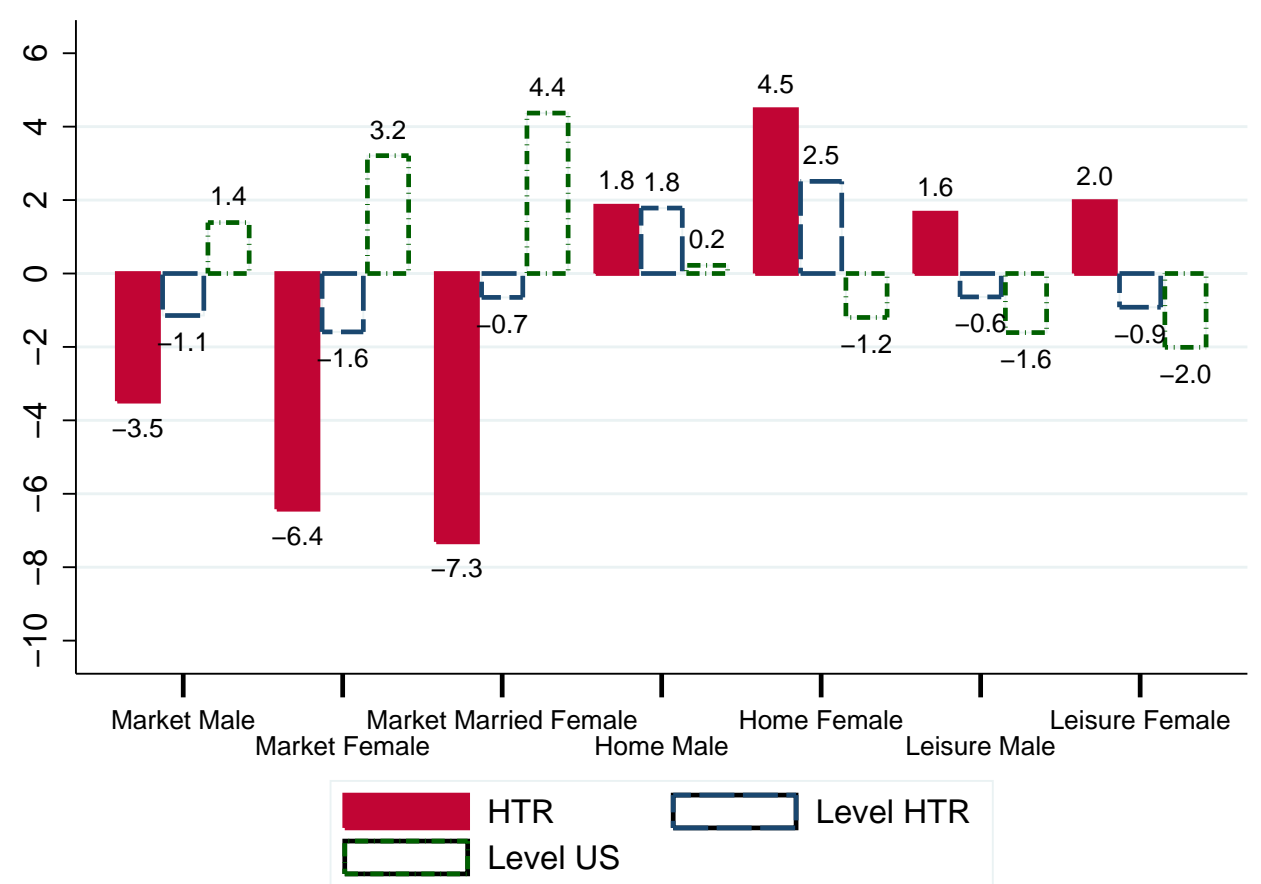

Note: Columns report the difference in weekly hours between the counterfactual and the 2007 benchmark values.

Figure 6: Tax Effects on Weekly Hours

tax with the same tax burden. In contrast, married couples and single men decrease home hours when eliminating progressivity.

In summary, taxes have a large negative effect on hours worked. The effect on hours differs across household types when modeling tax differences in levels or in both levels and progressivity. The results are consistent with the effects discussed in Section 5.

\subsection{Women, Taxes and the Rise of Services}

One aim of this study is to understand the importance of rising female market hours in explaining the size of the service sector. Since the benchmark model generates sizable labor market changes from 1977 to 2007 and different tax regimes have a sizable (but varying) impact on hours, the 
model is suitable to study the feedback effects between women, taxes and the rise of the service sector.

It the spirit of an Oaxaca-Blinder decomposition, it is possible to decompose the change in the hours ratio from Equation (22) by the exogenous technology component, machine demand, and relative goods-to-market service consumption. The change in the hours ratio $\left(\Delta_{T-0} \frac{L_{g}}{L_{s}}\right)$, from time period 0 to $T$ is,

$$
\Delta_{T-0} \frac{L_{g}}{L_{S}}=\underbrace{\left(A_{T}-A_{0}\right) \bar{X}}_{\text {Tech }_{X}}+\underbrace{\left(A_{T}-A_{0}\right) \bar{C}}_{\text {Tech }_{C}}+\underbrace{\left(X_{T}-X_{0}\right) \bar{A}}_{D_{X}}+\underbrace{\left(C_{T}-C_{0}\right) \bar{A}}_{D_{C}}
$$

where $A_{t}=\left(\frac{A_{s, t}}{A_{g, t}}\right)^{1-\alpha}, X_{t}=\frac{\alpha^{\frac{2}{1-\alpha}} A_{g, t}\left(L_{g, t}+L_{s, t}\right)}{C_{s, t}+K_{s, t}}, C_{t}=\frac{C_{g, t}+D_{t}}{C_{s, t}+K_{s, t}}, \bar{A}=\frac{A_{T}+A_{0}}{2}$, etc. The first two terms of Equation (25) capture changes due to a relative productivity increase in the goods sector, with the first accounting for the machine related change $\left(T e c h_{X}\right)$ and the second for the consumption related change $\left(\operatorname{Tech}_{C}\right)$. The last two terms capture changes due to demand shifts by firms in machine purchases $\left(D_{X}\right)$ and consumers $\left(D_{C}\right)$, respectively.

Table 8: Industry-to-Service Hours Trend Decomposition

\begin{tabular}{lcccccc} 
& Case & Total & Tech $_{X}$ & Tech $_{C}$ & $D_{X}$ & $D_{C}$ \\
\hline Benchmark & $(1)$ & 100 & 21 & 52 & -10 & 37 \\
\hline HTR & $(2)$ & 84 & 22 & 55 & -12 & 20 \\
Level HTR & $(3)$ & 93 & 21 & 53 & -11 & 30 \\
Level US & $(4)$ & 104 & 21 & 51 & -10 & 41 \\
\hline
\end{tabular}

Notes: Own computation using Equation (25).

Row (1) in Table 8 shows the corresponding decomposition for the benchmark. The consumption components (both technology and demand changes) account for 89 percent of the total fall in the hours ratio. Individually, changes due to technology and household demand account for 52 and 37 percent of the fall, respectively. As suggested by the theory, changes in machine demand lead to 
a rise in industry-to-service hours - the effect is 10 percent. The remaining 21 percent is accounted for by changes in technology related to the machine demand component. Rows (2) - (4) repeat the exercise with the three different counterfactual tax regimes. Higher taxes have a negative impact on relative consumption (last column) and, therefore, relative industry-to-service hours, which are $16(100-84)$ and $7(100-93)$ percentage points smaller, respectively. The difference between Rows (2) and (3) is explained by the smaller response in market hours under the flat tax scenario (see Figure 6). Similarly, Row (4) shows that using Level US taxes leads to a fall in industry-toservice hours 4 percentage points larger than in the benchmark. This result is driven exclusively by changes in household demand, which are driven by higher market hours for men and women. In conclusion, ignoring progressivity in taxes overestimates the feedback effect on the size of the service economy with women entering the labor market.

The understand the underlying differences across household types it is useful to further decompose the last column of Table 8. To do so, each column of Figure 7 reports the percent explained of the fall in industry-to-service hours from a "partial equilibrium" exercise assuming only one type of household (e.g., married) changes their consumption behavior over time.

In the benchmark, a fall in relative goods-to-service consumption of single males can only account for 32 percent $\left(\frac{12}{37}\right)$ of the consumption component affecting relative industry-to-service hours compared to 84 percent $\left(\frac{31}{37}\right)$ of married households. Single females have a slightly larger effect than single males, accounting for 43 percent of the total. The last column reports results for changing population shares with all consumption levels remaining at their 1977 levels. This experiment only accounts for 16 percent $\left(\frac{6}{37}\right)$ of the consumption component. The three tax experiments show similar relative contributions with some caveats. First, in the HTR experiment, single women can account for 55 percent $\left(\frac{11}{20}\right)$ of the consumption component. The fall in goods purchases is (in percentage terms) relatively large for single women in the HTR scenario, as hours shift from the market to home production. However, married households still account for most of the consumption change in the Level US and Level HTR scenarios, as married women's market 


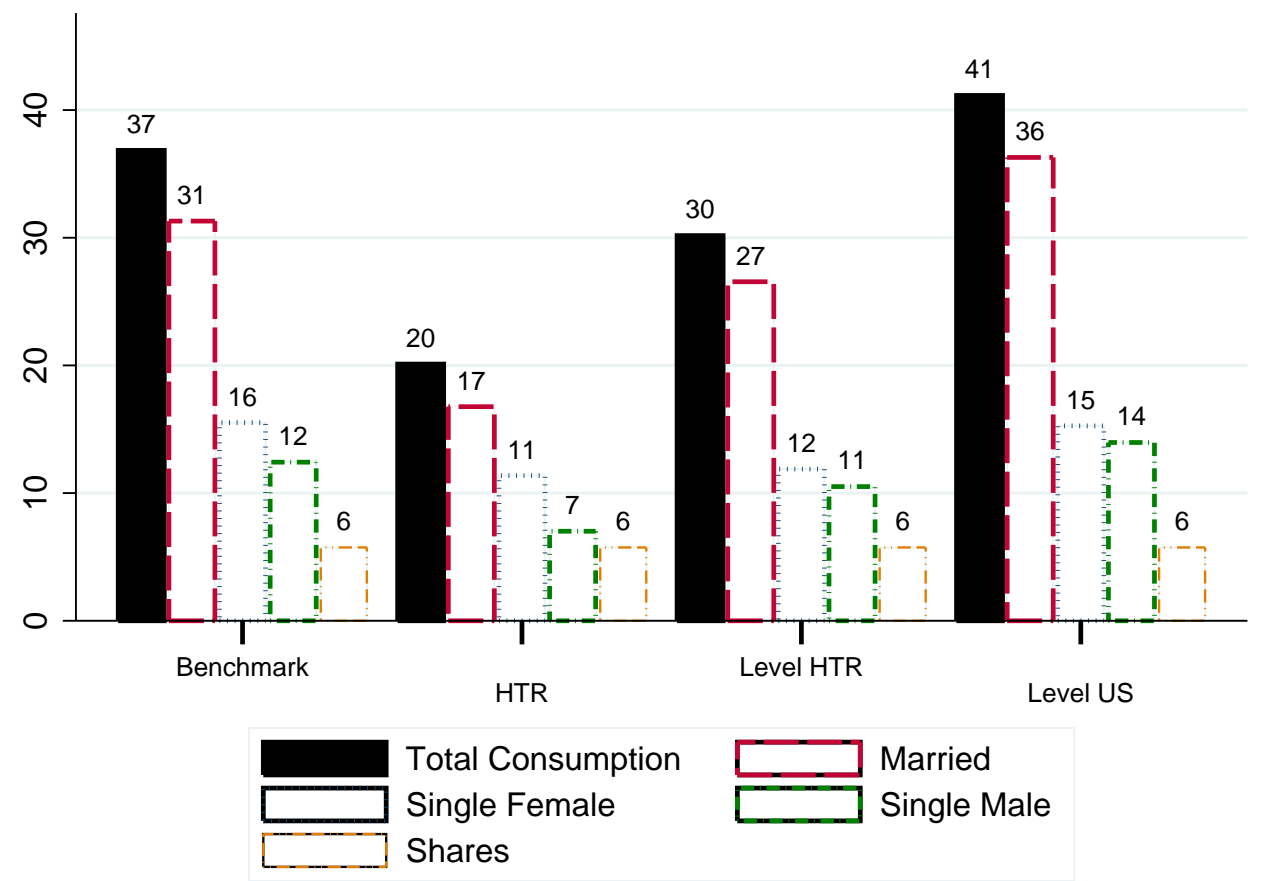

Note: Across the four tax regimes, first columns display the consumption component, $D_{X}$ from Equation (25). Columns (2) - (4) display the counterfactual consumption component by household type listed keeping all other household consumption fixed at the 1977 level. The last column displays the counterfactual consumption component by keeping household consumption fixed at 1977 and only adjusting shares of each household type from 1977 to 2007.

Figure 7: Household Specific Consumption Decomposition

hours rise with Level US taxes and marginally fall with Level HTR taxes (see Figure 6). Lastly, single men and women together can account for a larger share of changes in the relative consumption demand component in an economy with higher taxes, as secondary earners remain mostly specialized in home production.

In conclusion, the results highlight what a model without married households and only flat taxes would be missing. Accounting for married households is important, as these households make large adjustments to their consumption portfolio when women enter the labor market. Accounting for tax progressivity also matters as married and single households adjust hours on different margins depending on the tax regime. As explained in Section 5, this large adjustment in 
consumption comes from an earlier specialization, in market and home production, within dualadult households and a later outsourcing of home production to the market. This effect matters more when taxes are progressive.

\section{Conclusion}

This paper uses a standard multi-sector model with three major modifications: (1) households are either two-member households or single; (2) men and women differ in their productivity and preferences across sectors; and (3) households face tax schedules with level and progressivity differences. While this study includes some simplifying assumptions (e.g., abstracting from endogenous family formation or education), it fills a significant gap in the current literature by analyzing the combined effects of taxation, structural change, and women's work. That is, the model highlights the importance of favorable tax systems and the differences between revenue-equivalent flat and progressive tax regimes, particularly when studying the time trends in female hours and the size of the service sector.

More specifically, as the model does well in accounting for female hours and sector trends in the labor market, it is well suited to measure the feedback effect of women entering the labor market on the size of the service economy. The resulting estimates are non-negligible, with household demand changes accounting for over one-third of the growth in service-to-industry hours. The majority of the feedback effect comes from married women entering the work force and shifting consumption from the home to the market (e.g., childcare services, restaurant meals). Furthermore, counterfactual experiments show that taxes have a large negative impact on women's market hours and the size of the service economy. Higher taxes in the US would have led to only half the rise in (married) women's market hours and relative industry-to-service hours would be up-to 16 percent higher. Moreover, progressivity in taxes generate larger negative market outcomes than flat taxes, mostly due to a shift toward leisure in the former. 
The results presented here suggest that modeling only linear tax differences across time or countries may underestimate the effect of taxes on leisure hours, but overestimate the effect on home hours. Furthermore, as the results decomposed by household types show, modeling tax schedules with heterogeneity in terms of married versus single households is essential.

\section{References}

Acemoglu, Daron, and Fabrizio Zilibotti. 2001. "Productivity Differences.” The Quarterly Journal of Economics, 116(2): 563-606.

Aguiar, Mark, and Erik Hurst. 2007. "Measuring Trends in Leisure: The Allocation of Time over Five Decades.” The Quarterly Journal of Economics, 122(3): 969-1006.

Akbulut, Rahsan. 2011. “Sectoral Changes And The Increase In Women'S Labor Force Participation." Macroeconomic Dynamics, 15(02): 240-264.

Bick, Alexander, and Nicola Fuchs-Schuendeln. 2012. "Taxation and Labor Supply of Married Women across Countries: A Macroeconomic Analysis.” C.E.P.R. Discussion Papers CEPR Discussion Papers 9115.

Blau, Francine D., and Lawrence M. Kahn. 2007. "Changes in the Labor Supply Behavior of Married Women: 1980 - 2000.” Journal of Labor Economics, 25: 393-438.

Bridgman, Benjamin. 2016. "Home productivity." Journal of Economic Dynamics and Control, 71: $60-76$.

Buera, Francisco J., and Joseph P. Kaboski. 2012. "Scale and the origins of structural change." Journal of Economic Theory, 147(2): 684-712. 
Buera, Francisco J., Joseph P. Kaboski, and Min Qiang Zhao. 2013. "The Rise of Services: the Role of Skills, Scale, and Female Labor Supply.” National Bureau of Economic Research NBER Working Papers 19372.

Chakraborty, Indraneel, Hans A. Holter, and Serhiy Stepanchuk. 2015. "Marriage stability, taxation and aggregate labor supply in the U.S. vs. Europe.” Journal of Monetary Economics, 72(C): $1-20$.

Chang, Yongsung, and Frank Schorfheide. 2003. "Labor-supply Shifts and Economic Fluctuations." Journal of Monetary Economics, 50(8): 1751-1768.

Duernecker, Georg, and Berthold Herrendorf. 2015. "On the Allocation of Time - A Quantitative Analysis of the U.S. and France." CESifo Group Munich CESifo Working Paper Series 5475.

Esteban-Pretel, Julen, Ryo Nakajima, and Ryuichi Tanaka. 2011. "Are contingent jobs dead ends or stepping stones to regular jobs? Evidence from a structural estimation.” Labour Economics, 18(4): 513-526.

Fang, Lei, and Cara McDaniel. 2017. "Home hours in the United States and Europe." The BE Journal of Macroeconomics, 17(1).

Feenberg, Daniel, and Elisabeth Coutts. 1993. “An introduction to the TAXSIM model." Journal of Policy Analysis and Management, 12(1): 189-194.

Freeman, Richard B., and Ronald Schettkat. 2005. "Marketization of household production and the EU-US gap in work." Economic Policy, 20(41): 6-50.

Goldin, Claudia D. 1990. Understanding the Gender Gap : An Economic History of American Women. NBER Series on Long-term Factors in Economic Development. 
Grabka, Markus, and Joachim Frick. 2010. "Weiterhin hohes Armutsrisiko in Deutschland: Kinder und junge Erwachsene sind besonders betroffen.” DIW Wochenbericht, 77(7): 2-11.

Greenwood, Jeremy, and Nezih Guner. 2009. "Marriage and Divorce since World War II: Analyzing the Role of Technological Progress on the Formation of Households." In NBER Macroeconomics Annual 2008.

Guner, Nezih, Remzi Kaygusuz, and Gustavo Ventura. 2013. "Childcare Subsidies and Household Labor Supply.” Barcelona Graduate School of Economics Working Papers 738.

Holter, Hans A., Dirk Krueger, and Serhiy Stepanchuk. 2014. "How Does Tax Progressivity and Household Heterogeneity Affect Laffer Curves?" National Bureau of Economic Research, Inc NBER Working Papers 20688.

Jones, Larry E., Rodolfo E. Manuelli, and Ellen R. McGrattan. 2015. "Why Are Married Women Working so much?” Journal of Demographic Economics, 81(1): 75-114.

Kaldor, Nicholas. 1957. “A Model of Economic Growth.” The Economic Journal, 67(268): 591624.

Knowles, John A. 2013. "Why are Married Men Working So Much? An Aggregate Analysis of Intra-Household Bargaining and Labour Supply.” Review of Economic Studies, 80(3): 10551085.

McDaniel, Cara. 2011. "Forces Shaping Hours Worked in the OECD, 1960-2004." American Economic Journal: Macroeconomics, 3(4): 27-52.

McGrattan, Ellen R., Richard Rogerson, and Randall Wright. 1997. “An Equilibrium Model of the Business Cycle with Household Production and Fiscal Policy." International Economic Review, 38(2): 267-290. 
Mincer, Jacob, and Haim Ofek. 1982. “Interrupted Work Careers: Depreciation and Restoration of Human Capital." Journal of Human Resources, 17(1): 3-24.

Moro, Alessio, Solmaz Moslehi, and Satoshi Tanaka. 2017. "Does Home Production Drive Structural Transformation?" American Economic Journal: Macroeconomics, forthcoming.

Ngai, L. Rachel, and Barbara Petrongolo. 2017. "Gender Gaps and the Rise of the Service Economy." American Economic Journal: Macroeconomics, forthcoming.

Ngai, L. Rachel, and Christopher A. Pissarides. 2008. "Trends in Hours and Economic Growth." Review of Economic Dynamics, 11(2): 239-256.

OECD. 2015a. Economic Policy Reforms 2015: Going for Growth. OECD Publishing, Paris.

OECD. 2015b. "Taxes and benefits (Edition 2015)." OECD Social Expenditure Statistics (database).

OECD Committee on Fiscal Affairs. 1978. The Tax/benefit Position of Selected Income Groups in OECD Member Countries, 1972-1976: A Report. Organisation for Economic Co-operation and Development.

Olivetti, Claudia, and Barbara Petrongolo. 2014. "Gender Gaps across Countries and Skills: Supply, Demand and the Industry Structure." Review of Economic Dynamics, 17(4): 842 - 859.

Olovsson, Conny. 2009. "Why do Europeans Work so Little?" International Economic Review, 50(1): 39-61.

Petska, Ryan, Michael Strudler, and Tom Petska. n.d.. "Further Analysis of the Distribution of Income and Taxes, 1979-2002.” Statistics of Income Division, Internal Revenue Service.

Piketty, Thomas, and Emmanuel Saez. 2007. "How Progressive is the U.S. Federal Tax System? A Historical and International Perspective.” Journal of Economic Perspectives, 21(1): 3-24. 
Prescott, Edward C. 2004. "Why do Americans work so much more than Europeans?" Quarterly Review, Jul: 2-13.

Ragan, Kelly S. 2013. "Taxes and Time Use: Fiscal Policy in a Household Production Model." American Economic Journal: Macroeconomics, 5(1): 168-92.

Rendall, Michelle. 2017. "Brain versus Brawn: the Realization of Women’s Comparative Advantage.” Institute for Empirical Research in Economics - IEW IEW - Working Papers 491.

Rogerson, Richard. 2008. "Structural Transformation and the Deterioration of European Labor Market Outcomes.” Journal of Political Economy, 116(2): 235-259.

Schirle, Tammy. 2008. "Why Have the Labor Force Participation Rates of Older Men Increased since the Mid-1990s?” Journal of Labor Economics, 26(4): 549-594.

Whalen, Charles, and Felix Reichling. 2017. "Estimates of the Frisch Elasticity of Labor Supply: A Review." Eastern Economic Journal, 43(1): 37-42. 


\section{A Data Appendix: Simulation Input}

This appendix provides the CPS inputs (productivity levels and marital/parental shares of high school, some college, college, and post graduate individuals) of the US population in 1977 and 2007 for the simulation procedure.

Table A.1: Productivity Levels by Education Type

\begin{tabular}{clcccc} 
& & HS & SC & C & PG \\
\hline Young & & & & & \\
1978 & Male & 0.911 & 1.015 & 1.141 & 1.243 \\
& Female & 0.557 & 0.664 & 0.772 & 1.106 \\
2007 & Male & 0.685 & 0.884 & 1.200 & 1.491 \\
& Female & 0.523 & 0.704 & 1.042 & 1.485 \\
\hline \multirow{2}{*}{ Old } & & & & & \\
1978 & Male & 0.961 & 1.174 & 1.481 & 1.443 \\
& Female & 0.588 & 0.768 & 1.002 & 1.284 \\
2007 & Male & 0.802 & 1.022 & 1.386 & 1.675 \\
& Female & 0.612 & 0.814 & 1.204 & 1.668 \\
\hline
\end{tabular}

Note: 5-year moving averages. The sample of "Young" includes individuals aged 25 to 44 that worked at least 1,750 hours per year. The sample of "Old" includes individual fulltime workers aged 45 to 64 . See further notes in text for computation of full-time workers productivity levels. Source: CPS.

Table A.2: Single Female Shares by Education Type

\begin{tabular}{llcccc} 
& & HS & SC & C & PG \\
\hline \multirow{2}{*}{1978} & No Children & 0.031 & 0.011 & 0.010 & 0.012 \\
& 2 Children & 0.084 & 0.018 & 0.005 & 0.004 \\
\multirow{2}{*}{2007} & No Children & 0.025 & 0.027 & 0.030 & 0.017 \\
& 2 Children & 0.062 & 0.048 & 0.017 & 0.005 \\
\hline
\end{tabular}

Note: 5-year moving averages. The sample includes individuals aged 30 to 39. See further notes in text for computation of population shares. Source: CPS. 
Table A.3: Single Male Shares by Education Type

\begin{tabular}{ccccc} 
& HS & SC & C & PG \\
\hline 1978 & 0.070 & 0.029 & 0.019 & 0.022 \\
2007 & 0.102 & 0.062 & 0.045 & 0.018 \\
\hline
\end{tabular}

Note: 5-year moving averages. The sample includes individuals aged 30 to 39 . See further notes in text for computation of population shares. Source: CPS.

Table A.4: Married Shares by Education Type - No Children

HS $\quad$ SC $\quad$ C $\quad$ PG

\begin{tabular}{|c|c|c|c|c|}
\hline $\begin{array}{c}\text { HS Male } \\
1978 \\
2007\end{array}$ & $\begin{array}{l}0.024 \\
0.015\end{array}$ & $\begin{array}{l}0.005 \\
0.004\end{array}$ & $\begin{array}{l}0.003 \\
0.002\end{array}$ & $\begin{array}{l}0.001 \\
0.000\end{array}$ \\
\hline \multicolumn{5}{|l|}{ SC Male } \\
\hline $\begin{array}{l}1978 \\
2007\end{array}$ & $\begin{array}{l}0.003 \\
0.006\end{array}$ & $\begin{array}{l}0.003 \\
0.008\end{array}$ & $\begin{array}{l}0.002 \\
0.004\end{array}$ & $\begin{array}{l}0.002 \\
0.001\end{array}$ \\
\hline \multicolumn{5}{|l|}{ C Male } \\
\hline $\begin{array}{l}1978 \\
2007\end{array}$ & $\begin{array}{l}0.001 \\
0.004 \\
\end{array}$ & $\begin{array}{l}0.001 \\
0.006 \\
\end{array}$ & $\begin{array}{l}0.003 \\
0.013 \\
\end{array}$ & $\begin{array}{l}0.003 \\
0.005 \\
\end{array}$ \\
\hline \multicolumn{5}{|l|}{ PG Male } \\
\hline $\begin{array}{l}1978 \\
2007\end{array}$ & $\begin{array}{l}0.001 \\
0.002\end{array}$ & $\begin{array}{l}0.001 \\
0.003\end{array}$ & $\begin{array}{l}0.002 \\
0.006\end{array}$ & $\begin{array}{l}0.005 \\
0.008\end{array}$ \\
\hline
\end{tabular}

Note: 5-year moving averages. The sample includes individuals aged 30 to 39 . See further notes in text for computation of population shares. Source: CPS. 
Table A.5: Married Shares by Education Type - 2 Children

HS $\quad$ SC $\quad$ C $\quad$ PG

\begin{tabular}{ccccc} 
& HS & SC & C & PG \\
\hline HS Male & & & & \\
1978 & 0.317 & 0.063 & 0.029 & 0.015 \\
2007 & 0.111 & 0.025 & 0.010 & 0.002 \\
\hline $\begin{array}{c}\text { SC Male } \\
\text { 1978 }\end{array}$ & & & & \\
2007 & 0.030 & 0.030 & 0.022 & 0.019 \\
\hline C Male & & & & \\
1978 & 0.054 & 0.022 & 0.006 \\
2007 & 0.016 & 0.009 & 0.024 & 0.027 \\
\hline PG Male & & & & \\
1978 & 0.003 & 0.003 & 0.006 & 0.022 \\
2007 & 0.005 & 0.009 & 0.020 & 0.027 \\
\hline
\end{tabular}

Note: 5-year moving averages. The sample includes individuals aged 30 to 39 . See further notes in text for computation of population shares. Source: CPS. 


\section{SUPPLEMENTAL ONLINE APPENDIX}

NOT FOR PUBLICATION 


\section{O.1 Mathematical Appendix: Optimality Conditions}

Married households optimize by choosing $\left\{c_{g}, d, c_{s}, h_{m}, h_{f}, n_{m}, n_{f}\right\}$ and singles by choosing $\left\{c_{g}, d, c_{s}, h_{g}, n_{g}\right\}$ each period assuming the time constraints always bind. The first order conditions used to derive the analytical results in Section 5, derived from maximizing Equation (1) subject to the budget constraints (2) with multiplier $\xi$, are provided below.

The first order condition with respect to home hours for married individuals of gender $i, n_{i}$, is,

$$
\begin{aligned}
C^{1-\varepsilon-\phi} v_{p z}^{\phi-1}\left(1-a_{g}\right) F\left(\hat{c}_{s}, \hat{c}_{n}\right)^{\varepsilon-\rho}\left(1-a_{s}\right) \hat{c}_{n}^{\rho-1} & \times \\
A_{n}\left(a_{n} d^{\alpha_{d}}+\left(1-a_{n}\right) n^{\alpha_{d}}\right)^{\frac{1-\alpha_{d}}{\alpha_{d}}}\left(1-a_{n}\right) n^{\alpha_{d}-\alpha_{n}} n_{i}^{\alpha_{n}-1} & \\
& =\psi_{p} \ell^{1-\alpha_{\ell}-\sigma} \ell_{i}^{\alpha_{\ell}-1},
\end{aligned}
$$

and for market hours, $h_{i}$, it is,

$$
\xi \theta_{0, p z}\left(1-\theta_{1, p z}\right) y^{-\theta_{1, p z}} w \varepsilon_{i}=\psi_{p} \ell^{1-\alpha_{\ell}-\sigma} \ell_{i}^{\alpha_{\ell}-1}
$$

Combining Equations (O.1) and (O.2) for both spouses results in Equations (13) and (14) of relative time allocations (home hours and leisure) for a married couple. For a single individual the corresponding first order conditions are,

$$
\begin{gathered}
C^{1-\varepsilon-\phi} v_{s z}^{\phi-1}\left(1-a_{g}\right) F\left(\hat{c}_{s}, \hat{c}_{n}\right)^{\varepsilon-\rho}\left(1-a_{s}\right) \hat{c}_{n}^{\rho-1} \times \\
A_{n}\left(a_{n} d^{\alpha_{d}}+\left(1-a_{n}\right) n_{i}^{\alpha_{d}}\right)^{\frac{1-\alpha_{d}}{\alpha_{d}}}\left(1-a_{n}\right) n_{i}^{\alpha_{d}-1}=\psi_{s},
\end{gathered}
$$

and

$$
\xi \theta_{0, s z}\left(1-\theta_{1, s z}\right) y^{-\theta_{1, s z}} w \varepsilon_{i}=\psi_{s}
$$

The optimality condition for home capital, $d$, is,

$$
\begin{aligned}
& C^{1-\varepsilon-\phi} v_{p z}^{\phi-1}\left(1-a_{g}\right) F\left(\hat{c}_{s}, \hat{c}_{n}\right)^{\varepsilon-\rho}\left(1-a_{s}\right) \hat{c}_{n}^{\rho-1} \times \\
& A_{n}\left(a_{n} d^{\alpha_{d}}+\left(1-a_{n}\right) n^{\alpha_{d}}\right)^{\frac{1-\alpha_{d}}{\alpha_{d}}} a_{n} d^{\alpha_{d}-1}=\xi p_{g} .
\end{aligned}
$$

From Equation (O.2) we can solve for the multiplier $\xi$ and combining Equations (O.1), (O.5) and (13) results in Equation (15), which describes the relative capital to home-time allocation.

The first order condition for market-service consumption, $c_{s}$, is,

$$
C^{1-\varepsilon-\phi} v_{p z}^{\phi-1}\left(1-a_{g}\right) F\left(\hat{c}_{s}, \hat{c}_{n}\right)^{\varepsilon-\rho} a_{s} \hat{c}_{s}^{\rho-1}=\xi p_{s}
$$


and the equation for goods consumption, $c_{g}$, is,

$$
C^{1-\varepsilon-\phi} v_{p z}^{\phi-1} a_{g} c_{g}^{\varepsilon-1}=\xi p_{g}
$$

Equations (O.5) and (O.6) combine to Equation (17), the relative consumption of market-purchased to home-produced services, and Equations (O.6) and (O.7) combine to Equation (18), the relative market-purchased services-to-goods consumption. 